\title{
WestVirginiaUniversity
}

THE RESEARCH REPOSITORY @ WVU

Graduate Theses, Dissertations, and Problem Reports

1999

\section{Prediction of trauma responses following myocardial infarction}

Risa Nakase Thompson

West Virginia University

Follow this and additional works at: https://researchrepository.wvu.edu/etd

\section{Recommended Citation}

Thompson, Risa Nakase, "Prediction of trauma responses following myocardial infarction" (1999).

Graduate Theses, Dissertations, and Problem Reports. 3137.

https://researchrepository.wvu.edu/etd/3137

This Dissertation is protected by copyright and/or related rights. It has been brought to you by the The Research Repository @ WVU with permission from the rights-holder(s). You are free to use this Dissertation in any way that is permitted by the copyright and related rights legislation that applies to your use. For other uses you must obtain permission from the rights-holder(s) directly, unless additional rights are indicated by a Creative Commons license in the record and/ or on the work itself. This Dissertation has been accepted for inclusion in WVU Graduate Theses, Dissertations, and Problem Reports collection by an authorized administrator of The Research Repository @ WVU.

For more information, please contact researchrepository@mail.wvu.edu. 
Prediction of Trauma Responses Following Myocardial Infarction

Risa Nakase Thompson

Dissertation submitted to the

College of Arts and Sciences

at West Virginia University

in partial fulfillment of the requirements

for the degree of

Doctor of Philosophy

in

Clinical Psychology

Kevin Larkin, Ph.D., Chair

Stan Cohen, Ph.D.

Barry Edelstein, Ph.D.

Stanley Schmidt, M.D.

Joseph Scotti, Ph.D.

Department of Psychology

Morgantown, West Virginia

1999

Keywords: Myocardial Infarction, Post-traumatic Stress Disorder Copyright 1999 Risa Nakase Thompson 


\section{ABSTRACT \\ Prediction of Trauma Responses Following Myocardial Infarction \\ Risa Nakase Thompson}

For survivors of MI, the most common subsequent psychological complications include anxiety and depression. Recent interest has increased in examining the incidence of anxiety disorders, including Post-Traumatic Stress Disorder (PTSD), among post-MI patients. The purpose of this study was to prospectively evaluate trauma responses among a consecutive sample of post-MI patients. Forty - six post MI patients completed questionnaires and forty completed structured interviews during their initial hospitalization for MI. Six of these individuals reported acute stress disorder symptoms in response to their MI. These six patients scored significantly higher on most measures of PTSD. Thirty -two individuals completed a follow-up assessment of PTSD symptoms. Eight individuals $(30 \%)$ reported symptoms sufficient for a diagnosis of PTSD; five of whom had subclinical symptoms during Phase One. Younger age, lower levels of perceived social support from family, and less use of avoidant coping style significantly predicted PTSD measures at follow-up. Physician ratings of distress, perceived distress during MI, anticipated disability as a result of MI, and prior exposure to more traumatic events significantly correlated with PTSD measures, but they did not add unique variance in the regression models. Objective measures of the severity of the MI (peak cardiac enzymes, ejection fraction, and length of stay) did not correlate with number or severity of PTSD responses. Finally, prior exposure to traumatic events significantly predicted overall psychological distress. These findings suggest that PTSD is a common reaction to $\mathrm{MI}$ and that efforts to assess this treatable anxiety disorder, using multidisciplinary teams including mental health professionals should be encouraged. 


\section{Acknowledgments}

My sincerest appreciation to Kevin Larkin, Ph.D. who brought me into the home stretch in completing my graduate endeavor. I appreciate your patience and thank you for your guidance. Additional thanks to my individual committee members (Stan Cohen, Ph.D. Barry Edelstein, Ph.D. Stanley Schmidt, M.D. and Joseph Scotti, Ph.D.) for assisting me in improving the quality of this study. My thanks to all committee members for providing your time to assist me with this last milestone at WVU.

Special thanks goes to all of the fellows, residents, and medical students at West Virginia University School of Medicine who provided assistance with various aspects of data collection.

Additional thanks to various mentors (high school teachers, college professors/supervisors) who provided the groundwork early on in my life so that I would have the courage to do this. Their names are Robert Fabiano, M.A., Richard Bevel, B.S., Gloria Fisher, Ph.D., James Spivey, Ph.D., Patrick Smith, Ph.D., and Judy Lyons, Ph.D.

Final thanks to those individuals in my personal life that have indirectly supported my educational pursuit. My mother, Hiroko Thompson, who has always been an ideal role model for motivating me to keep trying harder. My sister, Genette Marie Thompson, who simply believes in me and who I have enjoyed so many precious and stress-relieving moments with the past few years. I love being your sister. My niece and nephew, Shelby and Taylor, who simply enrich my life. Finally to my best friend Albert Perry Bowles, M.D., for your friendship, guidance, and distraction from work this past year. I appreciate your ease at making me smile. 
Table of Contents

Title Page $\ldots \ldots \ldots \ldots \ldots \ldots \ldots \ldots \ldots \ldots \ldots \ldots \ldots \ldots \ldots \ldots \ldots \ldots \ldots \ldots \ldots$

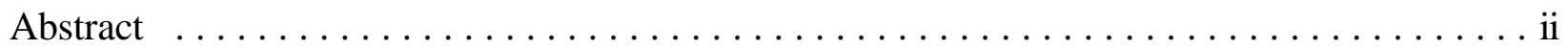

Acknowledgments $\ldots \ldots \ldots \ldots \ldots \ldots \ldots \ldots \ldots \ldots \ldots \ldots \ldots \ldots \ldots \ldots \ldots \ldots$ iii

Table of Contents $\ldots \ldots \ldots \ldots \ldots \ldots \ldots \ldots \ldots \ldots \ldots \ldots \ldots \ldots \ldots \ldots \ldots$

List of Tables $\ldots \ldots \ldots \ldots \ldots \ldots \ldots \ldots \ldots \ldots \ldots \ldots \ldots \ldots \ldots \ldots \ldots \ldots \ldots \ldots \ldots \ldots$

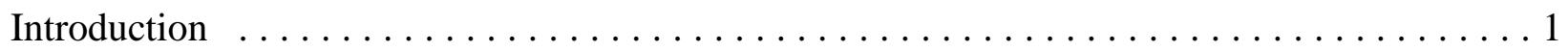

Clinical Presentation of MI $\ldots \ldots \ldots \ldots \ldots \ldots \ldots \ldots \ldots \ldots \ldots \ldots \ldots \ldots \ldots$

Psychological Complications Associated with MI $\ldots \ldots \ldots \ldots \ldots \ldots \ldots \ldots$

Myocardial Infarction and Trauma-Related Anxiety $\ldots \ldots \ldots \ldots \ldots \ldots \ldots$

Controversy of PTSD in Post-MI Patient $\ldots \ldots \ldots \ldots \ldots \ldots \ldots \ldots \ldots \ldots \ldots$

Review of Studies Assessing in Post-MI Patients $\ldots \ldots \ldots \ldots \ldots \ldots \ldots \ldots$

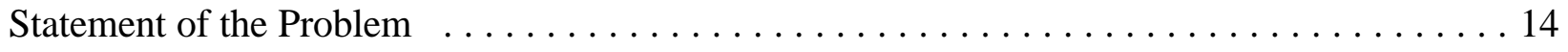

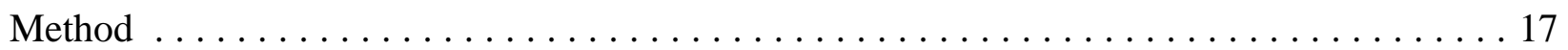

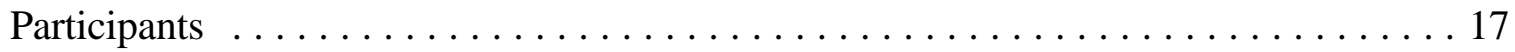

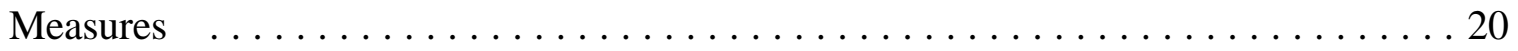

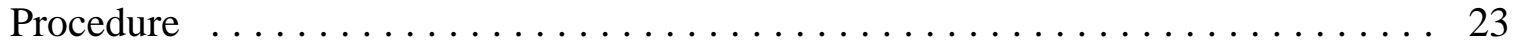

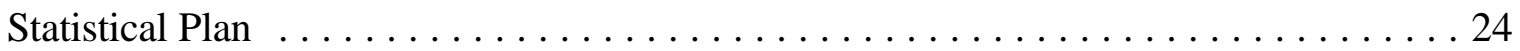

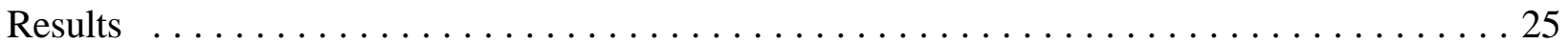

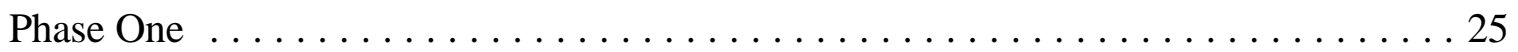

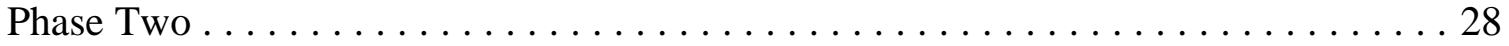

Phase One Predictors of Phase Two PTSD Responses $\ldots \ldots \ldots \ldots \ldots \ldots \ldots \ldots$ 


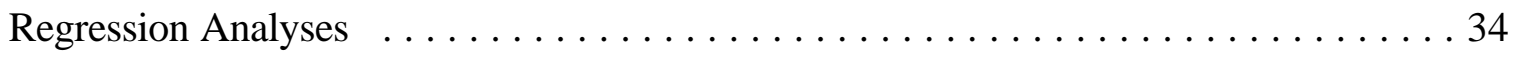

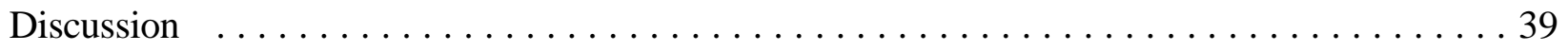

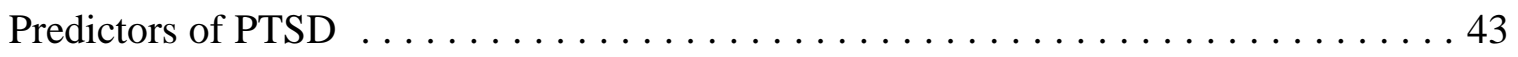

Concurrent Validation of PTSD Measures $\ldots \ldots \ldots \ldots \ldots \ldots \ldots \ldots \ldots$

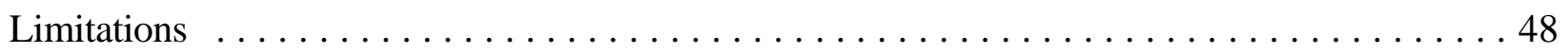

Significance of PTSD Symptoms Among Post-MI Individuals \& Future Directions . . . . . . 50

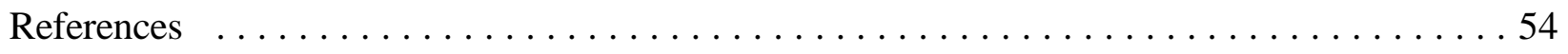

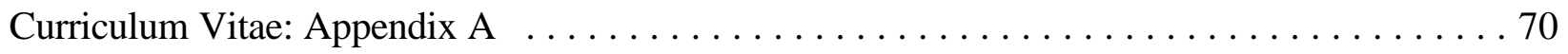


List of Tables

Table 1. Demographic Comparison For Individuals Completing and Not Completing Phase

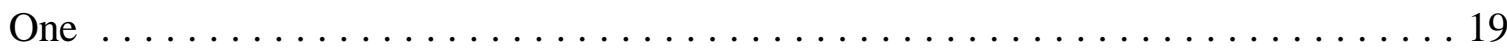

Table 2. ASD/PTSD Variables For Subjects With and Without ASD During Initial Hospitalization

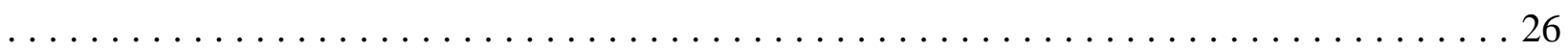

Table 3. Medical Variables For Subjects With and Without ASD Diagnoses During Phase One 27

Table 4. Correlation coefficient for Independent Variables and the Various Dependent Variables

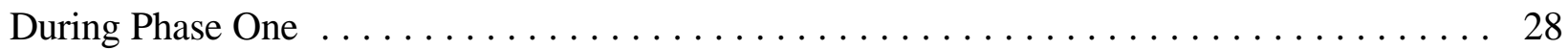

Table 5. Differences Between Individuals Completing and Not Completing Phase Two . . . . 29

Table 6. PTSD Variables for Participants With and Without ASD Diagnoses During Follow-Up30

Table 7. Correlations Among Various PTSD Measures During Phase Two . . . . . . . . . 32

Table 8. Correlation Coefficients for Potential Predictor Variable and Various Dependent

Variables During Phase Two $\ldots \ldots \ldots \ldots \ldots \ldots \ldots \ldots \ldots \ldots \ldots \ldots \ldots$

Table 9. Summary of Step-Wise Regression Analyses $\ldots \ldots \ldots \ldots \ldots \ldots \ldots \ldots$ 
Prediction of Trauma Responses Following Myocardial Infarction

Coronary heart disease (CHD) is the leading cause of death for men and women in western industrialized nations (Smith \& Leon, 1992). CHD is a condition in which the blood flow through the coronary arteries to the heart muscles is reduced resulting in either myocardial ischemia (e.g., angina) or myocardial infarction (MI; heart attack; Roberts, Morris, Pratt, \& Alexander, 1994). A MI occurs when a portion of the myocardium is deprived of its' blood supply for a period of time, resulting in the necrosis/death of heart muscle tissue. Approximately 1.5 million individuals experience a MI in the United States each year, and over 500,000 die from this disease annually (American Heart Association, 1989). This translates to 1,500 deaths per day or one fatality per minute. Since the 1960 's, CHD has been the leading cause of death in both men and women by the age of 40 and remains the number one killer of Americans throughout the remainder of life (Smith \& Leon).

\section{Clinical Presentation of MI}

The typical symptom profile for an individual experiencing an acute MI includes chest discomfort, described as aching, burning, crushing, squeezing, feeling heavy, or swelling up, and discomfort that radiates over the anterior of the chest and into the left or both arms and/or the neck or jaw (Roberts et al., 1994). Other symptoms may include dyspnea (difficult/labored respiration), diaphoresis (perspiration), nausea, vomiting, belching, syncope, acute confusion, agitation, palpitations, urge to defecate, and weakness/fatigue (Roberts et al.; Smith \& Leon, 1992). Despite the prevalence of these fairly obvious symptoms, in approximately one-quarter to one-third of all MI cases, symptoms are absent or non-specific symptoms go misinterpreted, and myocardial damage is only revealed on a subsequent electrocardiogram (ECG; Kannal \& Abbott, 
1984). Thus, a MI can vary across individuals in terms of symptoms experienced and presentation to the medical setting.

Psychological Complications Associated with MI

For survivors of MI, the most common subsequent psychological complications include anxiety and depression (Roberts et. al., 1994; Wenger, 1994). Estimates have revealed that approximately 40 to 80 percent of MI patients experience some type of emotional disturbance following their heart attacks (Byrne, \& Whyte, 1978; Cassem \& Hackett, 1971; Hackett \& Cassem, 1969; Lloyd \& Cawley, 1982; Naismith, Robinson, Shaw, \& McIntyre,1979; Rosen, \& Bibring, 1966; Stern, Pascale, \& McLoone, 1976; Wiklund, Sanne, Elmfeldt, Vedin, \& Wilhelmsson, 1984a; Wiklund, Sanne, Vedin, \& Wilhelmsson, 1984b). Specific disturbances cited have included depression, anxiety, irritability, excessive autonomic stimulation, disturbances in memory and concentration, preoccupation with cardiac problems, sleep disturbances, and nightmares (Byrne, \& Whyte, 1978; Cassem \& Hackett, 1971; Hackett \& Cassem, 1969; Lloyd \& Cawley, 1982; Naismith, et. al.,1979; Rosen \& Bibring, 1966; Stern et al., 1976; Wiklund, et al., 1984a; Wiklund, et al., 1984b). Although some level of emotional distress is considered a normal reaction post-MI, Lloyd and Cawley (1982) report that 20 to 30 percent of MI patients experience severe emotional disturbances. Whereas the symptoms experienced by most patients will dissipate two to three months post-MI, approximately 10 to $20 \%$ continue to experience distress for more extended periods of time (Lloyd \& Cawley, 1982; Rosen \& Bibrin, 1966; Wiklund et al., 1984). Following MI, anxiety and depression are believed to contribute to poor prognosis in cardiac rehabilitation, unsatisfactory life adjustment, failure to return to work, less interest in sexual activity, and reduced engagement in social activities subsequent to 
hospitalization (Brown \& Munford, 1984; Cay, Vetter, Philip, \& Dugard, 1973; Garrity, 1973;

Hacket \& Cassem, 1982; Mayou, 1984; Naismith et al., 1979; Trelawny-Ross \& Russell, 1987;

Wenger, 1994). In addition, recent studies have shown that individuals experiencing post-MI

psychological complications have increased rates of morbidity and mortality in comparison to patients without psychological complications (Allison et al., 1995; Frasure-Smith, 1991; FrasureSmith, Lesperance, \& Talajic, 1993, 1995; Moser \& Dracup, 1996; Vogt, Pope, Mullooly, \& Holis, 1994).

Interestingly, the level of emotional distress following MI seems unrelated to the severity of the heart attack; rather, the perception of the MI and its perceived impact upon future functioning better predicts who exhibits emotional distress following a heart attack (Lloyd \& Cawley, 1982; Sanne, 1986; Schleifer, Macari-Hinson, \& Coyle, 1989; Thompson, Webster, Cordle, \& Sutton, 1987).

\section{Myocardial Infarction and Trauma-Related Anxiety}

Although anxiety symptoms have been regularly reported in studies on post-MI patients, few studies have examined specific anxiety disorders that may develop as a consequence of MI. In particular, only a few studies exist that have examined the incidence of post-traumatic stress disorder in post-MI patients (Doerfler, Pbert, \& DeCosimo, 1994; Kutz, Shabtai, Solomon, Neumann, \& David, 1994; Neumann, 1991; van Driel \& Op den Velde, 1995). Post traumatic stress disorder (PTSD) is defined as a behavioral, cognitive, and physiological disturbance that follows a traumatic event causing significant impairment or distress. According to diagnostic criteria, the disturbance must last one month in duration; however, if the disturbance is less than 
one month in duration, a diagnosis of acute stress disorder (ASD) can be assigned (APA, Diagnostic and Statistical Manual IV, 1994).

Other studies have examined the incidence of PTSD following various medical illnesses, including cancer and severe burns (Alter, Pelcovitz, Axelrod, Goldenberg, Harris, Meyers, Grobois, Mandel, \& Kaplan, 1996; Shalev, Peri, Canetti, \& Schreiber, 1996). The medical course for each of these individual types of trauma is different from myocardial infarction; thus there may be a difference between them regarding incidence. For example, an individual with cancer may describe his or her trauma as a verbal exchange between the patient and physician when initial diagnosis was made. This appears to be qualitatively different from an individuals experiencing classic symptoms of MI such that they have sudden onset of various physical symptoms followed by the possibility of emergent treatments that are distressing and unexpected. In contrast, cancer patients may experience few and relatively benign symptoms at disease onset and have a more programmatic treatment course involving scheduled radiation therapy or chemotherapy courses. Fewer studies exist for individuals with burns. This type of medical problem is unique in that the physical signs of the illness are easily seen by the patient and may serve a qualitatively different cue for the individual traumatized by the burn experience. No studies to date have directly compared trauma experiences between these medical populations; however, the reported incidence of PTSD among them are comparable to those reported for MI (Kutz et al., 1994, van Driel \& Op den Velde, 1995).

Community-based studies have indicated a lifetime prevalence for PTSD related to all types of trauma ranges from 1 to $14 \%$ (variability due to methods of ascertainment and population sampled; Breslau, Davis, Andreski, \& Peterson, 1991; Helzer, Robins, \& McEvoy, 1987; 
Kilpatrick \& Resnick, 1992; Kulka et al., 1988). PTSD reactions have been observed in individuals exposed to various stressors, such as military combat, violent personal assault (e.g., sexual assault, physical attack, robbery, mugging), being kidnapped, being taken hostage, terrorist attack, torture, incarceration as a prisoner of war or in a concentration camp, natural or manmade disasters, severe automobile accidents, or being diagnosed with a life-threatening illness (Burgess \& Holmstom, 1974; Grene, Grace, Lindy, Gleser, Leonard, \& Kramer, 1990; Kilpatrick, Saunders, Veronen, Best \& Von, 1987; Smith, North, McCool, \& Shea, 1990; Winfield, George, Swartz, \& Blazer, 1990).

Not everyone exposed to these various types of events subsequently develops PTSD or ASD (Fairbank, Schlenger, Caddell, \& Woods, 1993). Prediction of the development of PTSD in response to stressors has been examined in many types of trauma survivors; however, predictors have been most scrutinized among Vietnam veterans (Fairbank et al., 1993; Ridley, 1991). Predictor variables of PTSD have included pre-trauma factors, trauma-related factors, and posttrauma factors (Fairbank et al., 1993). Pre-trauma factors include variables that were present prior to the traumatic event(s), such as age of entry into the military and drug or alcohol problems that may have existed for veterans prior to combat exposure (Fairbank et al., 1993). Trauma-related factors are variables concerning the traumatic event(s). For example, a study of PTSD among individuals exposed to the Mt. St. Helens eruption found a dose-response relation among PTSD symptoms and proximity to the mountain (Shore, Tatum, \& Vollmer, 1986). Post-trauma factors are considered variables that occur some time after the traumatic event. For example, studies of rape victims have demonstrated a positive relation between post-trauma social support and subsequent psychological adjustment (Atkeson, Calhoun, Resick, \& Ellis, 1982; Wirtz \& Harrell, 
1987). Research suggests that there is a role for each of these three categories of variables for understanding the development of PTSD (Fairbank et al., 1993; Scotti, Beach, Northrop, Rode, \& Forsythe, 1995).

Intensity and severity of the trauma have been consistent predictors across types of traumatic events (Ridley, 1991). For example, frequency and intensity of combat exposure (participation in atrocities, exposure to abusive violence) was a strong predictor of PTSD in combat veterans (Foy, Resnick, Sipprelle, \& Carroll, 1987). For adult rape survivors, intensity of initial distress, perceived life threat, and presence of physical injury were predictors of PTSD, and severity of abuse was an important factor affecting development of PTSD in child-incest victims (Kilpatrick, Veronen, \& Best, 1985; Kilpatrick et al., 1989; McCahill et al., 1979; Wolfe, Gentile, \& Wolfe, 1989). Although intensity and severity of trauma has been consistently linked to PTSD, it is uncertain whether this trauma-related factor serves as either a mediator or moderator of the relation between experience of trauma and PTSD onset. It's relation to predict PTSD may also differ depending upon the nature of the traumatic event and the time elapsed since the onset of the trauma (Feinstein \& Dolan, 1991; Perry et al., 1992; Ullman \& Siegel, 1994; Harvey \& Bryant, 1997).

Social support has also been shown to be a key variable in predicting PTSD across many types of trauma. Social support at home (particularly from ones' family) was important for post combat adjustment of veterans, and social support for rape survivors has been shown to have a significant impact on post-rape adjustment (Foy et al, 1987; Steketee \& Foa, 1987). Finally, unsupportive families has a negative impact on subsequent functioning for sexually abused children (Browne \& Finkelhor, 1986). Studies examining social support in PTSD populations 
purport that it serves as a buffer to the effects of stress including trauma-related stressors

(Golding et al., 1989; Joseph et al., 1992; Kaniasty \& Norris, 1992). To what extent social support serves to mediate or moderate the relation between experience of a traumatic event and PTSD onset is unknown. The identification of these common "risk factors" highlights that exposure to trauma alone is a necessary but not sufficient condition to predict subsequent development of a trauma reaction and that various factors serve as important predictors of who develops PTSD.

Controversy of PTSD in Post-MI Patients

The diagnosis of PTSD or ASD in post-MI patients is a controversial issue. Previous Diagnostic and Statistical Manuals (DSMs) did not permit classification of anxiety responses following MI, including PTSD, because MI was not considered an uncommon traumatic event (APA, Diagnostic and Statistical Manual III, 1980; APA, Diagnostic and Statistical Manual III-R, 1987; DSM-IV, 1994). As previously indicated, MI is very common and because past criteria required that a traumatic event be "out of the normal range of human experiences" or "so stressful that almost everyone exposed to it becomes distressed," trauma responses could not "technically" be diagnosed following MI until the DSM IV (1994). Significant changes in diagnostic criteria in the DSM-IV have refined the definition of PTSD and ASD to include traumatic events in which individuals respond with fear, helplessness, or horror. Further, individuals can experience, witness, or confront events that involve physical threat to others or self. As individuals suffering a MI may often exhibit fear or helplessness (van Driel \& Op den Velde, 1995), many of the descriptions of emotional upset in post-MI patients overlap with the diagnostic criteria for PTSD (e.g., anxiety, irritability, excessive autonomic stimulation, disturbances in memory, sleep disturbances, and 
nightmares (Byrne \& Whyte, 1978; Cassem \& Hackett, 1971; Hackett \& Cassem, 1969; Lloyd \& Cawley, 1982; Naismith et al.,1979; Rosen \& Bibring, 1966; Stern et al., 1976; Wiklund et al., 1984a; Wiklund, et. al., 1984b). Finally, because some individuals who suffer a heart attack do die, MI could easily be classified as a traumatic event according to the current criterion $\mathrm{A}$ in the DSM-IV (1994). Because of this recent change in the diagnostic system allowing MI or other lifethreatening medical illnesses to serve as a traumatic event, the literature on PTSD in cardiac patients is virtually non-existent in comparison to increasingly more studies examining the incidence of PTSD in cancer patients and caregivers of cancer patients (Andrykowski et al, 1998; Cordova, Studts, \& Amdrykowski, 1998; DuHamel et al., 1998; Manne et al., 1998). $\underline{\text { Review of Studies Assessing PTSD in Post-MI Patients }}$

Only four published studies have examined PTSD in post-MI patients.

The first study is by Neumann (1991) who compared PTSD symptoms between post-MI survivors and colonoscopy patients. During subsequent hospitalizations, 21 post-MI survivors and 20 colonoscopy patients completed a packet of questionnaires which included the Impact of Events Scale (IES), a checklist of diagnostic criteria for PTSD, and a Likert scale assessing subjective distress associated with MI or colonoscopy. Patients were a minimum of six months post-event ( $\underline{\mathrm{M}}=98$ months for MI patients; $\underline{\mathrm{M}}=29.9$ months for colonoscopy patients). Neumann reported that the post-MI group reported significantly more PTSD symptoms and obtained significantly higher scores on the IES than the post-colonoscopy group.

The use of a standardized PTSD measure is a strength for this study. Comparison to another medical patient group allowed the investigators to control other unpleasant aspects of illness and hospitalization that may influence psychological distress following a medical illness. 
However, receiving an unpleasant diagnostic test may not be comparable to receiving an imminent life-threatening diagnosis. Additionally, the retrospective nature of the design does not permit for assessment of acute distress that may be associated with complications during a time interval closer to the event. Post-MI survivors in this sample were an average of 8 years post-event. This sample may not be representative of the individuals who experience distress earlier in the stage of recovery from a traumatic event. Finally, the authors do not provide information regarding the subsequent diagnoses that individuals with higher questionnaire scores may have had. The mean IES scores reported fall below clinically significant levels.

Next, Kutz et al. (1994) assessed for the presence of PTSD in 100 Israeli MI patients selected from cardiology clinic files at a local hospital. Inclusion criteria included presence of (a) at least two out of the three diagnostic criteria for MI (typical clinical symptomatology, ECG evidence of MI, and typical elevated serum levels of myocardial enzymes), and (b) length of time elapsed since last MI ranging from 6 to 18 months $(\underline{M}=14$ months $)$. Participants were assessed using an adaptation of the PTSD Inventory (Solomon, 1989; Solomon, Mikulincer, \& Jacob, 1987) that was originally developed for use with combat veterans. Twelve of the original 13 items were used. The items consisted of statements regarding symptoms of PTSD adapted for use with MI patients. Additional information was collected from a semi-structured interview with psychiatrists, chart reviews, and other questionnaires that were not specified in the article.

Kutz et al. (1994) indicated that PTSD was present in 25 percent of the sample which is much higher than general population prevalence rates for PTSD (Helzer, Robins, \& McEvoy, 1987; Kilpatrick \& Resnick, 1992; Kulka et al., 1988). In their analysis, nine percent were 
diagnosed retrospectively as having suffered from acute PTSD that lasted less than six months and was not present at the time of examination. The remaining 16 percent were diagnosed with chronic PTSD. Using chi-square analyses, the authors reported that ethnic origin (Asian and Mediterranean), history of previous MI or previous cardiac hospitalization, and history of PTSD were related to the existence of current PTSD. No relation was found between PTSD and objective measures of the coronary event (e.g., degree of cardiac complications and necessity for cardiopulmonary resuscitation); however, the subjective rating by the patient regarding "anticipated incapacitation due to the MI" was significantly related with the development of PTSD. Specifically, individuals who anticipated more disability were more likely to develop PTSD. Other types of subjective experiences such as intensity of pain, degree of dyspnea, intensity of fear, and loss of consciousness were not significantly related to PTSD. Levels of dysfunction on all measures relating to post-MI work and social activities were strongly related to presence of PTSD in these post-MI patients.

The use of a large sample size is a major strength for this study; however, the assessment measures that were utilized represent a major weakness of this study. The authors used a PTSD measure that was originally developed with combat veterans. Although items were modified, no psychometric properties were reported. In addition, a semi-structured interview was employed; however, the authors did not state whether PTSD was assessed during the interview or what interview format was used. The authors reported that during the structured interview, they collected demographic information, medical history, life history, and subjective experiences of the MI from the patient's chart. The authors also did not report how subjective experiences of the MI were quantified and used in the statistical analyses. Although the findings of this study are 
provocative, the reliance upon the exact incidence of PTSD observed (i.e., 25\%) should be considered premature due to the numerous methodological limitations of this investigation.

Another study was conducted by van Driel and Op den Velde (1995) who assessed 23 individuals suffering from his or her first MI confirmed through medical tests. Participants were assessed one to two weeks following hospital admission and 22 to 26 months later. Participants with other major medical illnesses including previous MI were excluded. An initial structured interview was conducted by one of three psychiatry residents who used the SCID-R PTSD module (Spitzer \& Williams, 1985). Information regarding life history, social situation, prior traumatic experiences, and the subjective experience of the MI were additionally collected during the interview. Results indicated that during the initial interview (at 1-2 weeks), only one individual met criteria for acute stress disorder. Twelve participants had not realized that they were experiencing a heart attack during transportation to the hospital and reported no feelings of perceived life-threat, severe anxiety, or helplessness during this initial assessment. The follow-up assessment conducted approximately two years later was conducted by a psychiatry resident not involved in the initial examinations. The SCID-R PTSD module was again utilized and additional information regarding present condition, treatment, further developments, and subjective experience of the MI was also collected. Subject mortality included five individuals who died between assessments. The 12 individuals that had not realized they were experiencing a heart attack upon initial admission did not report any symptomatic distress at follow-up. Interview data revealed that 8 of 18 participants reported some distress during the first year after their MI, and two individuals sought psychiatric care. All of the distress-related symptoms reported by these individuals dissipated within two years of the MI. Two individuals who underwent cardioversion 
(discharge of electrical energy [shock] synchronized with the R-wave of the electrocardiogram) during initial MI were still preoccupied with the possibility of a second MI. According to the SCID-R PTSD module, none of the 18 individuals assessed at follow-up met criteria for PTSD after the two-year interval. The individual with ASD during the admission met criteria for PTSD in the first year after his MI, but did not meet criteria by the two-year interval.

Although this study employed a prospective design to assess the development of PTSD, considerable time passed between assessment intervals. As indicated above, many individuals retrospectively reported experiencing PTSD symptoms post-MI, yet the symptoms dissipated by the time the second assessment was conducted. In addition, the authors used a structured clinical interview with modest inter-rater reliability during the initial assessment, and the second assessment was conducted by a different psychiatrist with no information regarding his/her reliability with the original assessors. Additionally, no information was reported regarding how subjective information collected during the interview was quantified (i.e., subjective experience of the MI). Moreover, the smaller sample size employed could make it difficult to detect PTSD in this population. Finally, exclusion criteria for this study included other medical illnesses and previous MI. As indicated in the report by Kutz et al. (1994), one variable significantly associated with PTSD in this population was previous MI and cardiac-related hospitalization and testing; therefore, a selection bias could have resulted in the lower incidence of PTSD observed in this sample.

Finally, Doerfler et al. (1994) reported symptoms of PTSD in 50 patients that either were hospitalized for Coronary Artery Bypass Surgery (CABG; N=23) or had previously experienced a MI (time passed ranged 6 to 12 months; $\mathrm{N}=27$ ). Patients responded to a survey mailed to 115 
individuals. The survey package included the Reaction Index (RI; Frederick, 1985; checklist of various DSM-III PTSD symptoms), the Impact of Event Scale (IES; Horowitz, Wilner, \& Alvarez, 1979; items assess responses to stressful events), the Inventory to Diagnose Depression (IDD; Zimmerman \& Coryell, 1987; Zimmerman, Coryell, Corenthal, \& Wilson, 1986; items assess DSM-III-R range of depressive symptoms), the Trait Anxiety Inventory (TA; Spielberger, Gorsuch, Lushene, Vagg, \& Jacobs, 1983; items assess feelings of apprehension, worry, tension, and nervousness), the Trait Anger Scale (TAS; items assess frequency of anger as an emotion and individual differences in anger expression as a personality trait), the Symptom Check List - 90 (SCL-90; Derogatis, Lipman \& Covi, 1973; items assess broad range of psychopathology including anxiety, depression, somatization, hostility, interpersonal sensitivity, phobic anxiety, paranoid ideation, obsessive-compulsive symptoms, and psychoticism), and the Social Adjustment Scale (SAS; Weismann \& Bothwell, 1976; items assess instrumental or expressive role performance in work, social and leisure activities, relationship with extended family, marital role as spouse, parental role, and membership in family unity).

Doerfler et al. (1994) indicated that overall the distress levels in the group were quite low; however, several individuals reported high levels of PTSD symptoms on the RI and IES. Nine individuals had scores above seven on the RI which the authors suggest may indicate the presence of PTSD. Further, the authors attempted to compute an algorithm using the RI cutoff of seven, and items from the IES, IDD, and TAS to assess if individuals met all criteria for PTSD. Using this method, the authors determined that four individuals (three MI, and one CABG) met criteria for PTSD. 
Although Doerfler et al. (1994) utilized many valid self-report measures, the use of these measures to diagnose PTSD is questionable. The RI, in fact, was developed based upon the DSMIII criteria for PTSD, which has been mentioned earlier to rely on criterion different from current diagnostic criteria. Also because the authors reported the results of the study on both MI and CABG patients, it is difficult to ascertain the direct of effects of MI on PTSD symptoms.

\section{Statement of the Problem}

Although studies reviewed have various methodological weaknesses, thus far these studies support the hypothesis that MI may be a type of traumatic stressor that results in trauma responses such as PTSD or ASD. As discussed earlier, anxiety responses following MI have been observed in a large proportion of post-MI individuals and associated symptoms have included responses such as sleep disturbances, nightmares, excessive autonomic stimulation, irritability, disturbances in memory and concentration, and depression (Byrne \& Whyte, 1978; Cassem \& Hackett, 1971; Hackett \& Cassem, 1969; Lloyd \& Cawley, 1982; Rosen \& Bibring, 1966; Stern, Pascale, \& McLoone, 1976; Wiklund et al., 1984a; Wiklund et al.,1984b). All of these symptoms could describe post-trauma adjustment. For example, re-experiencing of a trauma may take the form of nightmares, and persistent arousal may be manifested by sleep disturbances, irritability, and difficulty concentrating.

Recent studies have shown increased risk of mortality and morbidity for individuals with post-MI psychological complications (Frasure-Smith, 1991; Frasure-Smith, Lesperance, \& Talajic, 1993; Allison et al., 1995; Frasure-Smith, Lesperance, \& Talajic, 1995; Vogt et al.,1994; Moser \& Dracup, 1996; Sullivan et al., 1997 ). Exploring the incidence of anxiety responses such as PTSD in this population could reveal a similar relation between post-MI anxiety responses and 
increased risk of morbidity or mortality. Identification and treatment of PTSD in these individuals may improve recovery from MI and lower mortality resulting from cardiac complications.

The literature examining PTSD following MI has been limited in part due to past restrictions in diagnostic criteria. Four group studies have attempted to examine the incidence of trauma responses in the form of symptoms or diagnoses (PTSD or ASD); however, the methodological weaknesses of these studies obscure the estimation of an accurate description of PTSD in post-MI individuals.

This current study was designed to overcome some of the methodological limitations associated with previous studies. Individuals in this study were assessed during the acute recovery phase and three to four months immediately post-MI in order to prospectively collect data regarding trauma responses. Valid diagnostic instruments were used to assess the incidence of PTSD/ASD in a consecutive sample of participants with a recent history of MI. The measures of PTSD/ASD included the Post-traumatic Stress Disorder Scale (PSD), a standardized self-report instrument that was developed for use with various types of traumatic events. The scale allowed for assessment of specific diagnostic criteria and provided a checklist of previous traumatic events that an individual may have experienced. A standardized clinical interview for PTSD was used to ascribe a diagnosis of ASD or PTSD during the assessment intervals. Additionally, the Impact of Events Scale was selected because it has been used in previous studies examining responses to stressful events in this population. These instruments were selected for their utility in assessing incidence of PTSD/ASD prospectively or traumatic responses to stressful events among individuals during the acute hospitalization and approximately 3-4 months post-MI. Also included 
was the SCL-90-R, a broad measure of psychopathology that has been used in other studies with this population (Doerfler et al., 1994).

Secondly, variables that have been shown to predict trauma responses across types of trauma (i.e., rape, combat, \& incest as mentioned earlier) were assessed during Phase One (initial hospitalization following MI) and used in combination with other predictors of PTSD responses and post-MI maladjustment to predict trauma responses as measured by PTSD questionnaires and structured interview during Phase Two of the study.

Perceived social support and perceived distress associated with MI were among the potential predictor variables chosen for this study. Social support was selected because it has consistently been shown to have a significant inverse relation with distress associated with traumatic events including myocardial infarction ( Brezinka \& Kittel, 1998; Foy et al, 1987; Schaefer, Coyne, \& Lazarus, 1981; Solomon, Mikulincer, \& Avitzur, 1986; Steketee \& Foa, 1987,). Additionally, perceived life threat and distress has been positively correlated with development of PTSD symptomatology (Foy et al., 1987; Kilpatrick et al., 1985; Kilpatrick et al., 1989). Additionally, Kutz et al. (1994) reported a significant positive relation between perceived distress and disability associated with MI and subsequent development of PTSD symptoms; however, the authors did not report how they measured this variable. Thus, visual analogue scales, frequently used to quantify subjective ratings, were utilized to assess perceived distress and disability associated with MI.

Coping styles and severity of traumatic events have less consistently served as reliable predictors of psychological distress associated with PTSD and distress associated with MI. However, coping styles have repeatedly been investigated in studies examining psychological 
distress associated with MI and were assessed for the purposes of this study using similar measurement instruments of coping styles (Alonzo \& Reynolds, 1998). Further, severity of MI has not been specifically investigated in PTSD and MI studies but was included in this study to assess it's viability as a potential predictor for this unique type of trauma (i.e., medical illness). Finally, additional variables such as socioeconomic data, history of previous traumatic events, psychiatric problems, family instability, and substance abuse were assessed to determine their relation with psychological distress in post-MI patients.

It was hypothesized that (1) some MI patients will report trauma responses across the various measures of ASD/PTSD at both initial data collection and follow up, and (2) variables that were predictive of PTSD symptoms with other types of traumatic events will serve a similar function for the prediction of PTSD symptoms in post-MI patients. For example, it was hypothesized that low levels of perceived social support would be predictive of distress post-MI. Further, higher levels of perceived distress associated with MI would be predictive of subsequent PTSD/ASD symptoms.

Method

\section{Participants}

Eighty-six individuals with a history of recent myocardial infarction who were treated at Ruby Memorial Hospital in Morgantown, WV were approached to consent to participate in the study. All patients on the Cardiology Service who were at least 18 years of age and had a recent history ( $<2$ weeks) of MI were approached. Eight individuals were excluded from the study because they had a diagnosis of possible cognitive disorder $(\mathrm{N}=6)$, or were the recipient of an implantable cardioverter defibrillator $(\mathrm{N}=2)$. Eight participants declined to participate. Of the 70 
participants initially consenting to participate, 46 completed the questionnaire component of Phase One and 40 completed the questionnaires and the diagnostic interview. Table 1 depicts information obtained from a demographic questionnaire and chart reviews for individuals completing Phase One. Information obtained included transfer status, age, ethnicity, gender, marital status, current employment, income level, history of psychological problems for individual or family members, and responses to general questions regarding alcohol and illicit substance abuse.

Information regarding the MI experience such as date, duration in hospital, associated complications, treatments received, and knowledge of experiencing a MI during the episode was also recorded. Information regarding the severity of the MI was collected from the participant's chart during or following their hospitalization. Some participants in the study did not have this information available in the medical record at the participating hospital or did not receive a test to determine severity variables such as ejection fraction (17 missing), degree of heart damage as estimated by peak cardiac enzyme level (CPK, 10 missing), and previous medical history (i.e., prior MI; 1 missing). Individuals who completed Phase One did not differ from the noncompleters on the basis of age, years of education, or variables assessing severity of MI. However, participants who were approached earlier in their hospital stay were less likely to complete Phase One than those who were approached later (see Table 1). Of the 46 participants who completed Phase One, 14 did not complete either the follow-up questionnaires or telephone interview (Phase Two). A total of 32 individuals completed the interview ( $\mathrm{N}=26)$, the questionnaires $(\mathrm{N}=32)$ or both $(\mathrm{N}=24)$ during Phase Two. 
Table 1. Demographic Comparison for Individuals Completing and Not Completing Phase One.

\begin{tabular}{|c|c|c|c|c|}
\hline Demographics & $\frac{\frac{\text { Phase One }}{\text { Completers }}}{\mathrm{N}=46}$ & $\begin{array}{l}\frac{\text { Phase One }}{\text { Non-Completers }} \\
\mathrm{N}=24\end{array}$ & $\underline{\mathrm{t}}$ & $\underline{p}$ \\
\hline Mean Age ${ }^{1}$ & $59.3(15.6)$ & $63.3(14.1)$ & .45 & .50 \\
\hline Mean Years of Education ${ }^{2}$ & $11.46(3.5)$ & $11.3(2.8)$ & .18 & .67 \\
\hline CK (CPK; peak creatine kinase) $)^{3}$ & $1603(1917)$ & $1354(1146)$ & .30 & .12 \\
\hline Length of Stay (LOS; days) ${ }^{4}$ & $7.7(4.3)$ & $6.5(3.3)$ & .52 & .47 \\
\hline Ejection Fraction $^{5}$ & $44.1(14.9)$ & $47.1(11.6)$ & .49 & .47 \\
\hline Time Since MI (days) ${ }^{6}$ & $5.7(6.1)$ & $2.7(2.1)$ & 6.1 & $.01 *$ \\
\hline Gender (Male) & $65.2 \%$ & $58 \%$ & - & - \\
\hline Mean Income $(\mathrm{N}=23)$ & $22,729(22,063)$ & - & & \\
\hline Marital Status & $\begin{array}{l}32 \text { Married } \\
8 \text { Widowed } \\
6 \text { Div/Sep/Single }\end{array}$ & - & & \\
\hline $\begin{array}{l}\text { Occupational } \\
\text { Status }\end{array}$ & $\begin{array}{l}13 \text { Employed } \\
7 \text { Unemployed } \\
24 \text { Retired } \\
2 \text { Disability/Other }\end{array}$ & - & & \\
\hline $\mathrm{H} / \mathrm{O}$ ETOH $(\mathrm{N}=45)$ & $13 \%$ & - & & \\
\hline H/O Illicit Drug Use $(\mathrm{N}=44)$ & $6.5 \%$ & - & & \\
\hline $\mathrm{H} / \mathrm{O}$ Psychiatric/Self $(\mathrm{N}=44)$ & $13 \%$ & - & & \\
\hline H/O Psychiatric/Family (N=43) & $8.7 \%$ & - & & \\
\hline Was Pt Transferred & $45.7 \%$ & - & & \\
\hline
\end{tabular}


Measures

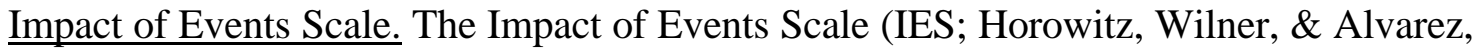
1979 ) is a 15-item scale on which participants rate the impact of a traumatic or stressful event. The IES has two subscales which assess the intrusive domain (IES-Intrusive Subscale; e.g., recurring thoughts) and the avoidance domain (IES-Avoidance Subscale; e.g., avoid stimuli associated with traumatic event) associated with PTSD, thus yielding two subscale scores for the questionnaire. The IES has overall acceptable test-retest reliability (.87) and internal consistency (e.g., Cronbach's alpha, .78 for the intrusion score and .82 for the avoidance items, with an overall split-half reliability correlation of .86 (Horowitz et. al., 1979), and has been used in many previous studies examining PTSD (Kulka et al., 1988; Schwarzwald, Solomon, Weisenber, \& Milulincer, 1987).

Posttraumatic Stress Diagnostic Scale. The Posttraumatic Stress Diagnostic Scale (PSD) is a 49-item self-report instrument designed to aid in the diagnosis of posttraumatic stress disorder (Foa, 1995). The PSD is designed to yield a PTSD diagnosis if a respondent endorses all DSM-IV criteria assessed in the questionnaire, and specifiers regarding acute, chronic, or delayed onset of PTSD; however, if responses are not sufficient to meet criteria for PTSD, the diagnosis score is rated as "Not Enough Information" instead of "No PTSD." Additionally overall number and severity of symptoms is yielded along with number and severity of symptoms associated with the diagnostic categories for (a) avoidance, (b) intrusive thoughts, (c) hyperarousal, and (d) functional impairment (Foa, 1995). Finally, the PSD contains a checklist of previous traumatic events that assesses exposure to previous trauma and the individual's perceived worst traumatic event for which he/she refers to when responding for the duration of the questionnaire. For this reason, the 
PSD was modified during Phase Two so that the individual responding reported symptoms associated with their MI as a traumatic event and not other possible traumatic events they may have experienced. The PSD has been shown to have overall good test-retest properties (.83), and good internal consistency for the symptom severity subscale (alpha of .92). The PSD obtained a 79.4\% agreement with clinical interviews obtaining diagnoses of PTSD (using SCID), and the symptom severity score was also found to have good convergent validity with measures of depression (coefficent=.79), anxiety (.73 - .74), and intrusive thoughts (.80; Foa, 1995).

Anxiety Disorders Interview Schedule for DSM-IV, PTSD Module. The Anxiety Disorders Interview Schedule (ADIS), PTSD Module has received some empirical support in the area of PTSD diagnosis (DiNardo, O'Brien, Barlow, Waddell, \& Blanchard, 1983). The ADIS-IV is a structured clinical interview developed to assess PTSD using DSM-IV criteria (Brown, DiNardo, \& Barlow, 1994). After its completion, diagnoses such as PTSD and ASD are determined by a clinician and not by an algorhythm of symptoms. Due to it's recent emergence, there are no studies published regarding reliability; however, previous versions have been reported to have good psychometric properties (Bouman \& de Ruiter, 1991; Di Nardo et al., 1993). Perceived Social Support. The Perceived Social Support -Friend Scale (PSS-Fr) and Perceived Social Support-Family Scale (PSS-Fa) are two 20-item instruments that assess the degree that one perceives his/her needs for support as fulfilled by one's network of friends as well as family (Procidano \& Heller, 1983). Higher scores on each subscale indicate higher levels of perceived support. The PSS has excellent internal consistency (alpha .88 and .90 respectively) for PSS-Fr and PSS-Fa, and overall test-retest reliability coefficients over a one-month time period have been reported at .83 for a preliminary version of the scale which constituted the same items 
from both scales. Both scales have good discriminant validity with measures of social assets (Fr: = .23 to $.51 ; \mathrm{Fa}=.12$ to $.35 ;$ Procidano $\&$ Heller, 1983$)$.

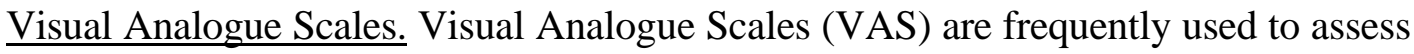
intensity of variable constructs including pain and anxiety (Arntz, Merckelback, \& de Jong, 1993; Feldman, 1986; Holmes, 1989; Thomas, McEwen, \& Asbury, 1996). The Kutz et al. (1994) study assessed intensity of perceived distress associated with MI; however, they did not specify how they measured this variable. For the purposes of this study, VASs were selected to assess perceived distress associated with MI. The VAS for this study was constructed using a 10mm line with anchors on each end to facilitate rapid ranking of multiple response questions. Participants used a VAS to (a) rate the amount of distress experienced during their MI (VAS I), (b) rate the amount of perceived life threat (VAS II), and (c) rate the amount of anticipated disability they experienced during the MI episode (VAS III). Higher scores on the VAS indicated higher levels of distress, perceived life threat, or higher anticipation of disability.

Symptom Checklist - 90-R. The Symptom Checklist-90-R (SCL-90-R) is a 90-item selfreport symptom inventory designed to reflect the psychological symptom patterns of psychiatric and medical patients (Derogatis, 1977). Each item is rated on a 5-point scale of distress from $0=$ "Not at All" to 4="Extremely." The measure yields nine primary symptom dimensions (somatization, obsessive-compulsive, interpersonal sensitivity, depression, anxiety, hostility, phobic anxiety, paranoid ideation, \& psychoticism) and three global indices of distress (global severity index, positive symptom distress index, \& positive symptom total). The SCL-90-R has internal consistency coefficients ranging from .77 to .90 for the subscales, and test-retest properties ranging from .78-.90 for the subscales. Doerfler et al. (1994) used the SCL-90-R as a 
distress measure; thus it was utilized for a similar purpose in this current study. However, only the GSI was used as the index of generalized distress due to its stability across factor analytic studies (Derogatis, 1977)

Ways of Coping Checklist - Revised. The Ways of Coping Checklist-Revised (WCCL-R; Vitiliano et. al., 1985) is a 42-item scale with five factor-analytically derived subscales: Problem Focused (actively seeks solutions to problems), Seeks Social Support (actively seeks assistance from others), Blamed Self (frequent negative cognitions blaming self for problem; emotion focused), Wishful Thinking (frequent cognitions for how a problem may be resolved; emotion focused), and Avoidance (behavior and cognitions indicating avoidance of a problem). The WCCL-R has internal consistency coefficients ranging from .74 to .88 for subscales (Vitiliano et al., 1985). Increased use of a particular coping strategy is indicated by a higher score on any particular subscale.

SUDS. A small sample of physicians (residents) were queried regarding patients level of distress using a SUDS (subjective units of distress) rating (1-100) to quantify the perception of distress each participant was experiencing during his or her initial hospitalization. Higher ratings indicate higher levels of distress. Only 32 of the 46 individuals completing Phase One received a SUDS rating by their physician. Consequently, this variable was excluded from some analyses and served primarily a descriptive purpose.

$\underline{\text { Procedure }}$

All prospective cardiology patients admitted between February 1997 to June 1997 who met at least two out of the three diagnostic criteria for MI (typical clinical symptomatology, ECG evidence of MI, and typical elevated serum levels of myocardial enzymes) were approached by the 
primary investigator to obtain consent for participation. After informed consent was obtained, the participant was asked to complete an initial package of questionnaires and undergo the structured interview using the ADIS-IV PTSD module. Because the assessment packet was lengthy, individuals were provided a self-addressed stamped envelope to return uncompleted portions by mail. The questionnaire packet for Phase One included Perceived Social Support Scale-Family version, Perceived Social Support Scale-Friend version, Symptom Checklist-90-Revised, Ways of Coping Checklist-Revised, Posttraumatic Stress Disorder Scale, Impact of Events Scale, and Visual Analogue Scales I-III.

Approximately 3.0 to 3.5 months following the subject's date of their MI, an abbreviated version of the questionnaire packet and self-addressed stamped envelope was mailed to all participants to complete and return to the investigators. The questionnaire packet at Phase Two included: Symptom Checklist-90-Revised, Impact of Events Scale, and Posttraumatic Stress Disorder Scale. Approximately 1-2 weeks following mailing of the packet, participants were called by phone to complete the interview portion of the study again. If participants were unavailable at the initial phone interview, attempts were made to continue to make phone contact. If participants did not complete the initial packet within approximately one month following the initial mailing, a second packet was mailed. The average time elapsed for follow-up contact was 24 weeks $(\mathrm{SD}=6.2 ;$ range $=15$ to 46$)$.

\section{$\underline{\text { Statistical Plan }}$}

Simple t-tests and analysis of variance with bonferroni correction were used to compute differences between groups completing the various phases of the study for descriptive purposes. Next, all of the potential predictors (IVs) were correlated with the PTSD measures (DVs) and the 
IES subscales (DVs). All potential IVs that were signficantly correlated with the various DVs were entered concurrently into a stepwise multiple regression equation to assess which IVs would account for the most variance among the DVs. Finally, all IVs were correlated with the most sensitive measure of the SCL-90-R, the GSI. All of the IVs that were signficantly correlated with the GSI were entered into a stepwise multiple regression equation to assess which variables would account for the most variance in global distress.

\section{Results}

\section{$\underline{\text { Phase One }}$}

Using the ADIS-IV Module, six individuals (15\%) were diagnosed with acute stress disorder as a result of their MI during initial hospitalization. Thirty-four participants (85\%) did not meet criteria for ASD associated with their MI (ASD-MI) during hospitalization. Table 2 reveals the scores for the various ASD/PTSD measures during Phase One for the non-ASD and ASD-MI groups. On the PSD, the ASD-MI group had a higher number and severity of reexperiencing symptoms, number and severity of avoidance symptoms, severity of arousal symptoms, number of areas of impairment, and overall number and severity of symptoms than the non-ASD-Mi group. No significant differences were found between the two groups on the Impact of Event subscales, number of arousal symptoms reported, and prior history of traumatic event exposure.

Table 3 depicts the medical variables related to history of cardiac problems, current cardiac interventions, and variables illustrating the severity of the participant's MI. In addition, a portion of the sample received a rating indicating the physician's perception of the participant's 
26

Table 2. ASD/PTSD Variables for Participants with and without ASD Diagnosis During Initial Hospitalization (Phase One)

\begin{tabular}{|c|c|c|c|c|}
\hline$\underline{\text { ASD/PTSD Measures }}$ & $\frac{\text { Non-ASD Group }}{(\mathrm{N}=34)}$ & $\frac{\text { ASD Group }}{(\mathrm{N}=6)}$ & $\underline{F}$ & $\underline{p}$ \\
\hline \multicolumn{5}{|l|}{ Impact of Events Scale } \\
\hline IES-Avoidance Subscale & $10.6(11.6)$ & $18.0(12.5)$ & 1.8 & .18 \\
\hline IES-Intrusion Subscale & $9.6(9.6)$ & $14.8(11.2)$ & 1.1 & .80 \\
\hline \multicolumn{5}{|c|}{ Posttraumatic Stress Disorder Scale } \\
\hline Exposure to Traumatic Events & $2.8(1.9)$ & $3.0(1.5)$ & .0 & .86 \\
\hline Number of Re-experiencing Sx (B) & $1.3(1.6)$ & $3.0(1.5)$ & 5.2 & $.02^{*}$ \\
\hline Severity of Re-experiencing Sx & $2.0(2.7)$ & $6.6(4.1)$ & 12.4 & $.00 *$ \\
\hline Number of Avoidance Sx (C) & $1.7(2.2)$ & $4.0(2.5)$ & 5.2 & $.02 *$ \\
\hline Severity of Avoidance Sx & $2.2(2.7)$ & $8.1(6.7)$ & 13.5 & $.00^{*}$ \\
\hline Number of Arousal Sx (D) & $1.4(1.4)$ & $2.5(1.0)$ & 3.4 & .07 \\
\hline Severity of Arousal Sx & $2.0(2.1)$ & $5.2(2.8)$ & 9.5 & $.00^{*}$ \\
\hline Areas of Impairment from PSD & $3.8(4.2)$ & $8.0(2.4)$ & 5.3 & $.02 *$ \\
\hline Overall No. of Sx & $4.4(4.5)$ & $9.5(4.8)$ & 6.1 & $.02 *$ \\
\hline Overall Sx Severity & $7.0(7.7)$ & $19.8(12.5)$ & 10.9 & $.00^{*}$ \\
\hline
\end{tabular}

Note. Categories are based on ADIS-IV PTSD Module; Six participants did not complete the ADIS-IV PTSD interview during phase one. 
Table 3. Medical Variables for Participants with and without ASD Diagnosis During Initial Hospitalization (Phase One).

\begin{tabular}{|c|c|c|}
\hline Medical Variables & $\frac{\text { Non-ASD Group }}{(\mathrm{N}=34)}$ & $\frac{\text { ASD Group }}{(\mathrm{N}=6)}$ \\
\hline Emergent TX & 10 & 1 \\
\hline Current CABG TX & 5 & 0 \\
\hline H/O CABG TX & 4 & 0 \\
\hline PTCA TX & 26 & 4 \\
\hline H/O PTCA TX & 7 & 0 \\
\hline Stent TX & 14 & 2 \\
\hline H/O Stent TX & 1 & 0 \\
\hline TPA & 2 & 1 \\
\hline Defibrillation & 3 (1 awake) & 0 \\
\hline (+)Complications & 11 & 2 \\
\hline Length of Stay (days) & 6.9 & 6.8 \\
\hline CPK (Mean Value) & $1768(1923)$ & $967(959)$ \\
\hline Ejection Fraction (percent) ${ }^{1}$ & 48 & 46 \\
\hline $\begin{array}{c}\text { Mean Physician Ratings }{ }^{2} \\
(0-100 \text { SUDS })\end{array}$ & 39.8 & 74.0 \\
\hline
\end{tabular}

Note. Categories are based on ADIS-IV PTSD Module; $\mathrm{N}=6$ participants did not complete the ADIS-IV PTSD interview during Phase One; ${ }^{1} \mathrm{~N}_{\mathrm{ASD}}=5, \mathrm{~N}_{\mathrm{NASD}}=22 ;{ }^{2} \mathrm{~N}_{\mathrm{ASD}}=5, \mathrm{~N}_{\mathrm{NASD}}=25$ 
distress. The physician rating is the only medical variable that was significantly different between the two groups during Phase One $[\underline{\mathrm{F}}(1,28)=17.9, \underline{\mathrm{p}}=.0001]$.

Table 4 indicates the degree of relation between potential predictor variables and the various measures of ASD during phase one. Significant inverse relations were observed between ASD measures and age, post-MI assessment interval, seeks social support subscale from the WCCL-R, and perceived social support from family (PSS-FA). Positive correlations were observed between one or more of the ASD measures and number of pre-morbid traumatic events, physician ratings, perceived distress and disability (VAS I-III).

$\underline{\text { Phase Two }}$

Of the 46 participants who completed Phase One, 32 completed follow-up questionnaires and 26 completed the follow-up structured interview (Phase Two). Using simple t-tests with a Bonferronni correction, no differences were detected on demographic variables, medical variables, or psychological variables assessed during Phase One between the completers and noncompleters of Phase Two (see Table 5 ).

During Phase Two, ADIS-IV interviews indicated eight individuals (30\%) reported symptoms sufficient to meet criteria for PTSD - three of whom met criteria for ASD during their hospitalization and five individuals who did not meet criteria for ASD during Phase One. Two individuals who met criteria for ASD during Phase One did not complete Phase Two. One individual who met criteria for ASD during Phase One, did not have sufficient symptoms to meet criteria for PTSD during Phase Two. 
Table 4 . Correlation Coefficients for Independent Variables and the Various Dependent Variables at Phase One.

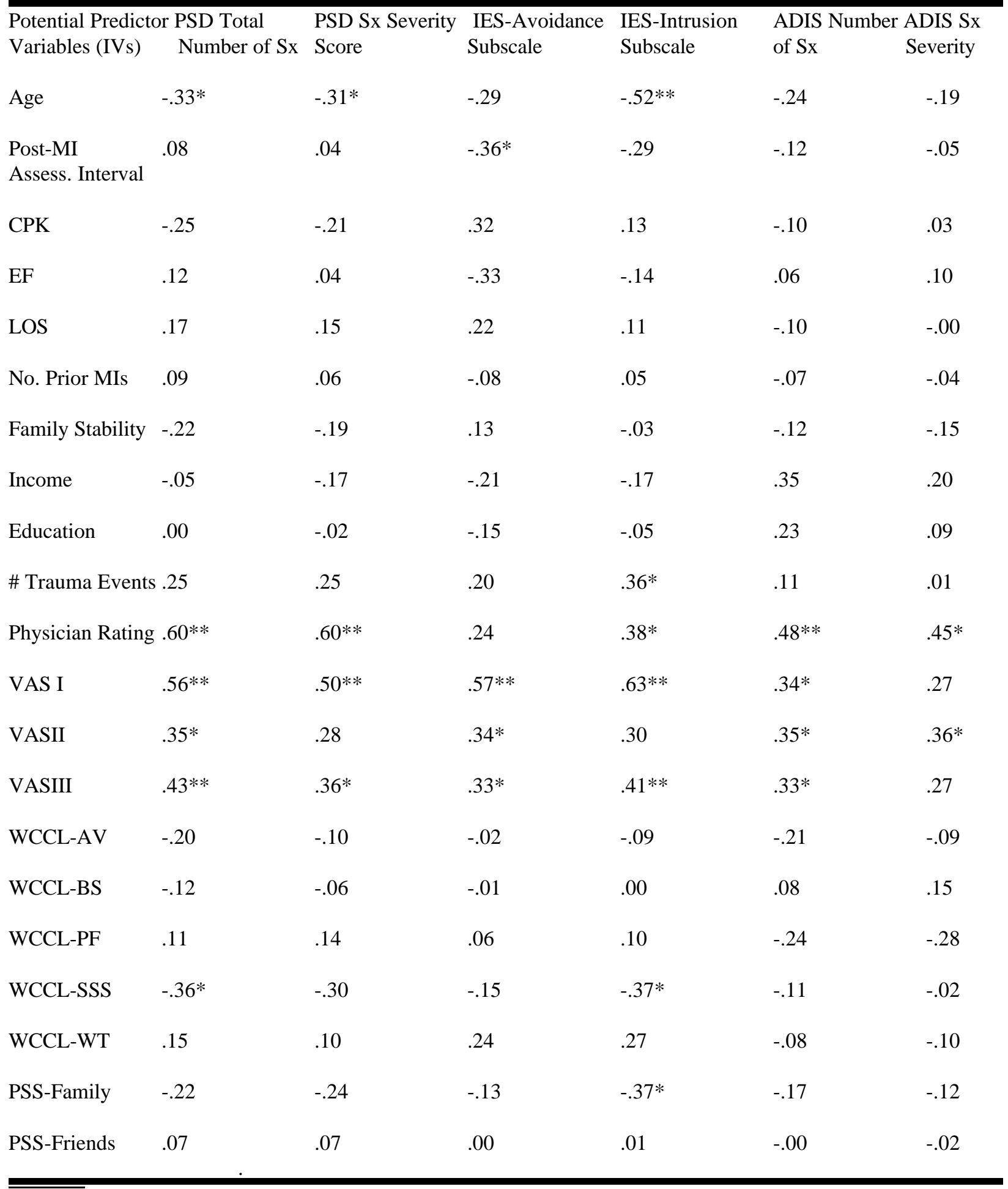


30

Table 5. Differences Between Individuals Completing and Not Completing Phase Two.

\begin{tabular}{|c|c|c|c|c|}
\hline$\underline{\text { Variables }}$ & $\frac{\mathrm{P} 2 \mathrm{C}}{(\mathrm{N}=32)}$ & $\frac{2 \mathrm{NC}}{(\mathrm{N}=14)}$ & $\underline{\mathrm{t}}$ & $\underline{p}$ \\
\hline Age (years) & $57.6(16.7)$ & $63.2(14.8)$ & 1.3 & .26 \\
\hline Education (years) & $11.5(2.5)$ & $11.0(5.6)$ & .16 & .69 \\
\hline CK $(\mathrm{CPK} \text {; peak creatine kinase })^{1}$ & $1688.0(2187.0)$ & $1052.9(1012.4)$ & .76 & .38 \\
\hline Length of Stay (days) & $7.8(4.7)$ & $7.6(2.9)$ & .01 & .91 \\
\hline Ejection Fraction $(\mathrm{EF} \text {; percent })^{2}$ & $42.5(15.2)$ & $47.8(15.5)$ & .62 & .43 \\
\hline Time Since MI (days) & $5.3(5.4)$ & $7.1(8.3)$ & .61 & .44 \\
\hline Physician Ratings ${ }^{3}$ & $46.0(17.7)$ & $41.1(27.1)$ & .37 & .54 \\
\hline VAS 1 (MM; distress) & $41.8(38.7)$ & $28.0(35.8)$ & .98 & .33 \\
\hline VAS 2 (MM; concerned/death) & $33.9(37.4)$ & $22.8(35.3)$ & .72 & .40 \\
\hline VAS 3 (MM; disability) & $31.1(38.9)$ & $26.7(41.3)$ & .10 & .75 \\
\hline IES-A & $13.4(12.0)$ & $8.2(11.1)$ & 1.3 & .25 \\
\hline IES-I & $11.3(10.0)$ & $4.8(6.1)$ & 3.2 & .07 \\
\hline PSD-Number Sx & $5.6(4.9)$ & $4.7(4.4)$ & .32 & .57 \\
\hline ADIS-Number of $\mathrm{Sx}^{4}$ & $4.3(3.7)$ & $3.4(3.9)$ & .36 & .55 \\
\hline No. Previous. Trauma Events & $2.8(1.9)$ & $2.4(1.6)$ & .45 & .50 \\
\hline SCL: GSI ${ }^{5}$ & $2.14(7.4)$ & $.69(.60)$ & .37 & .54 \\
\hline
\end{tabular}

Note. ${ }^{1} \mathrm{~N}_{\mathrm{P} 2 \mathrm{C}}=24, \mathrm{~N}_{\mathrm{P} 2 \mathrm{NC}}=10 ;{ }^{2} \mathrm{~N}_{\mathrm{P} 2 \mathrm{C}}=21, \mathrm{~N}_{\mathrm{P} 2 \mathrm{NC}}=7 ;{ }^{3} \mathrm{~N}_{\mathrm{P} 2 \mathrm{C}}=23, \mathrm{~N}_{\mathrm{P} 2 \mathrm{NC}}=9 ;{ }^{4} \mathrm{~N}_{\mathrm{P} 2 \mathrm{C}}=30 ; \mathrm{N}_{\mathrm{P} 2 \mathrm{NC}}=10 ;{ }^{5}$ $\mathrm{N}_{\mathrm{P} 2 \mathrm{C}}=31 ; \mathrm{N}_{\mathrm{P} 2 \mathrm{NC}}=10$. 
31

Table 6. PTSD Variables for Participants with and without PTSD Diagnosis During Follow-Up (Phase Two).

ASD/PTSD Measures

Non-PTSD

PTSD

$\underline{F}$

$\mathrm{p}$

$(n=17)$

$(n=7)$

$\underline{\text { Impact of Events Scale }}$

IES-Avoidance Subscale

$5.82(8.5)$

$11.86(8.5)$

$2.59 \quad .13$

IES-Intrusion Subscale*

$5.89(6.9)$

$15.71(7.1)$

$9.82 \quad .00$

$\underline{\text { Posttraumatic Stress Disorder Scale }}$

Number of Re-experiencing Sx (B)* .94 (1.5)

$3.57(1.3)$

$16.90 \quad .00$

Severity of Re-experiencing $\mathrm{Sx}^{*}$

$1.65(3.0)$

$5.29(2.6)$

$7.79 \quad .01$

Number of Avoidance Sx (C)*

$1.71(2.1)$

$4.43(1.7)$

$9.26 \quad .00$

Severity of Avoidance Sx*

$2.59(3.6)$

$7.14(3.8)$

$8.54 \quad .01$

Number of Arousal Sx (D)*

$1.6(1.6)$

$3.43(1.5)$

$6.86 \quad .02$

Severity of Arousal Sx

$3.24(3.6)$

$4.86(3.9)$

$1.04 \quad .31$

Areas of Impairment from PSD

$3.18(3.9)$

$6.00(4.1)$

$5.90 \quad .02$

Overall No. of Sx*

$4.23(4.5)$

$11.43(3.7)$

$14.01 \quad .00$

Overall Sx Severity*

$7.30(8.9)$

$18.43(8.9)$

$7.94 \quad .01$

Note. Sample size changes due to one subject in each group who did not complete the IES and PSD accurately. 
Table 6 provides results of trauma-related questionnaires during Phase Two between the two diagnostic groups. Individuals with PTSD has significantly higher scores on the Intrusion subscale of the Impact of Events Scale. On the PSD, the PTSD group had higher overall number and severity of PTSD symptoms, number and severity of re-experiencing symptoms, number and severity of avoidance symptoms, number of arousal symptoms and areas of impairment. On the SCL-90-R, the PTSD group had higher scores on the somatization, obsessive-compulsive, interpersonal sensitivity, depression, anxiety, hostility, phobic anxiety, paranoid ideation, and psychoticism subscales. Significant group differences were also observed on overall indices of distress: GSI, PST, and PSDI (see Table 7).

Table 7 shows the relation between the various PTSD measures obtained during Phase Two. All of the measures were significantly inter-correlated except for the number of ADIS-IV symptoms endorsed and the IES-Avoidance subscale; however, strength of the relations varied between all measures.

Phase One Correlates of Phase Two PTSD Responses

Correlations between variables assessed at Phase One and the PTSD measures administered during Phase Two are shown in Table 8. Significant positive correlations were observed between various PTSD measures and history of traumatic events, physician ratings of distress, perceived distress (VAS I) and disability (VASIII). Indirect relations were observed between various PTSD measures and age, WCCL-R Avoidance Subscale, WCCL-Seeks Social Support, and Perceived Social Support -Family subscale. Finally, significant direct correlations were observed between number of previous traumatic events and physician ratings of distress with 
33

Table 7. Correlations Among the Various PTSD measures at Phase Two.

\begin{tabular}{|c|c|c|c|c|c|c|}
\hline & $\begin{array}{l}\text { PSD Total } \\
\text { Number of Sx }\end{array}$ & $\begin{array}{l}\text { PSD Sx Severity } \\
\text { Score }\end{array}$ & $\begin{array}{l}\text { IES-Avoidance } \\
\text { Subscale }\end{array}$ & $\begin{array}{l}\text { IES-Intrusion } \\
\text { Subscale }\end{array}$ & $\begin{array}{l}\text { ADIS Number } \\
\text { of Sx }\end{array}$ & $\begin{array}{l}\text { ADIS Sx } \\
\text { Severity }\end{array}$ \\
\hline $\begin{array}{l}\text { PSD Total } \\
\text { Number of SX }\end{array}$ & & $.91 * *$ & $.74 * *$ & $.77 * *$ & $.61^{* *}$ & $.58 * *$ \\
\hline $\begin{array}{l}\text { PSD Sx } \\
\text { Severity Score }\end{array}$ & & & $.81 * *$ & $.84 * *$ & $.51 * *$ & $.58 * *$ \\
\hline $\begin{array}{l}\text { IES-Avoidance } \\
\text { Subscale }\end{array}$ & & & & $.83 * *$ & .32 & $.43^{*}$ \\
\hline $\begin{array}{l}\text { IES-Intrusion } \\
\text { Subscale }\end{array}$ & & & & & $.45^{*}$ & $.54 * *$ \\
\hline $\begin{array}{l}\text { ADIS Number } \\
\text { of SX }\end{array}$ & & & & & & $.87 * *$ \\
\hline
\end{tabular}


the SCL-90-R GSI and a significant indirect correlation was observed between the SCL-90-R GSI index and age.

\section{$\underline{\text { Regression Analyses }}$}

Variables that were significantly correlated with the various PTSD measures were selected for entry into stepwise regression analyses to determine which variable (or combination of variables) best correlated with PTSD symptoms during Phase Two. Because physician ratings of distress during initial hospitalization were not available for several patients (missing for $\geq 10$ individuals completing Phase Two), this variable was not used in these analyses. Only variables with significant correlations with the PTSD measures were entered into the regression equations. Separate regression analyses were computed for the AIDS-IV PTSD Interview (number and severity of symptoms), Impact of Events Scale (intrusion and avoidance subscales), Posttraumatic Stress Disorder Scale (number and severity of symptoms), and the SCL-90-R GSI Index.

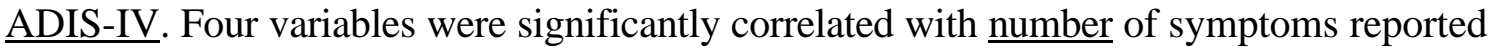
during the ADIS-IV PTSD interview ( age, PSS-Fa, number of traumatic events experienced prior to MI, and VAS-3; distress rating for "perceived disability" as a result of MI.) thus were entered into a step-wise regression model. Table 9 shows that age and PSS-Family score accounted for approximately 48 percent of the variance in number of symptoms reported during ADIS-IV interview.

Three variables showed significant correlations with severity of symptoms reported during the follow-up ADIS-IV interview and were entered into a stepwise regression analysis (age, PSS$\mathrm{Fa}$, and number of traumatic events). Table 9 again shows that age and perceived social support 
35

Table 8. Correlation Coefficients for Medical, Psychosocial, and Demographic Variables and the Various Dependent Variables at Phase Two.

\begin{tabular}{|c|c|c|c|c|c|c|c|}
\hline Potential IVs & $\begin{array}{l}\text { PSD T } \\
\# \text { of Sx }\end{array}$ & $\begin{array}{l}\text { tal PSD Sx Severity } \\
\text { Score }\end{array}$ & $\begin{array}{l}\text { IES- } \\
\text { Subsc }\end{array}$ & oidance & $\begin{array}{ll}\text { IES-Intrusion } & \text { ADIS \# } \\
\text { Subscale } & \text { of Sx }\end{array}$ & $\begin{array}{l}\text { ADIS Sx } \\
\text { Severity }\end{array}$ & $\begin{array}{l}\text { SCL-90 } \\
\text { GSI }\end{array}$ \\
\hline Age & $-.50 * *$ & $-.54 * *$ & $-.40 *$ & $-.52 * *$ & $-.59 * *$ & $-.71 * *$ & $-.60 * *$ \\
\hline CPK & -.09 & -.08 & -.19 & -.14 & .29 & .42 & -.16 \\
\hline $\mathrm{EF}$ & -.04 & -.11 & -.14 & -.08 & .24 & .16 & .03 \\
\hline LOS & -.26 & -.09 & .11 & .01 & -.15 & -.05 & -.09 \\
\hline $\begin{array}{l}\text { No. Prior } \\
\text { MIs }\end{array}$ & -.19 & -.23 & -.20 & -.26 & -.20 & -.21 & -.31 \\
\hline $\begin{array}{l}\text { Family } \\
\text { Stability }\end{array}$ & -.15 & -.22 & -.18 & -.13 & .11 & .15 & -.24 \\
\hline Income & -.07 & -.14 & .23 & -.10 & -.13 & -.04 & -.21 \\
\hline Education & .13 & .13 & .13 & .18 & .01 & .10 & .04 \\
\hline $\begin{array}{l}\text { \#Trauma } \\
\text { Events }\end{array}$ & $.42 *$ & $.43 *$ & .24 & $.46^{*}$ & $.51 * *$ & $.48^{*}$ & $.62 * *$ \\
\hline $\begin{array}{l}\text { Physician } \\
\text { Rating }\end{array}$ & $.82 * *$ & $.71 * *$ & $.71 * *$ & $.67 * *$ & $.54 *$ & $.62 * *$ & $.63 * *$ \\
\hline VAS I & $.42 *$ & .35 & .29 & .22 & .28 & .23 & .33 \\
\hline VASII & .10 & .09 & -.00 & -.02 & .28 & .23 & .12 \\
\hline VASIII & .26 & .10 & .09 & -.02 & $.39 *$ & .36 & .12 \\
\hline WCCL-AV & -.26 & $-.40 *$ & $-.42 *$ & $-.39 *$ & .12 & .16 & -.28 \\
\hline WCCL-BS & -.39 & $-.41 *$ & -.31 & -.32 & .15 & .03 & -.21 \\
\hline WCCL-PF & -.12 & -.06 & -.01 & .00 & .08 & .15 & .15 \\
\hline WCCL-SSS & -.32 & $-.39 *$ & -.28 & -.26 & -.20 & -.26 & -.36 \\
\hline WCCL-WT & .08 & .02 & -.01 & .11 & .25 & .08 & .05 \\
\hline PSS-Family & -.25 & -.22 & -.26 & -.25 & $-.57 * *$ & $-.57 * *$ & -.33 \\
\hline PSS-Friends & -.03 & .03 & -.01 & .27 & -.10 & -.02 & .01 \\
\hline
\end{tabular}

Note. $*$ significant at .05 level $* *$ significant at .01 level $(\mathrm{EF}=$ Ejection Fraction; $\mathrm{LOS}=$ Length of Stay; WCCL: BS=Blames Self, PF=Problem Focused, SSS=Seeks Social Support, WT=Wishful Thinking) 
from family members accounted for $58 \%$ of the variance in severity of symptoms reported during the PTSD interview.

Impact of Events Scale. Three variables were significantly correlated with the Intrusion subscale of the IES and were entered into a stepwise regression analyses (age, Avoidance Subscale of the WCCL-R, and number of traumatic events). Table 9 indicates that age and WCCL-Avoidance subscale accounted for $51 \%$ of the variance in IES-Intrusion Scores. The IES-Avoidance subscale correlated significantly with age and the WCCL-Avoidance subscale. These two variables were entered into a stepwise regression; Table 9 shows the results of the regression. Age and Avoidance Coping accounted for $39 \%$ of the variance in IES-Avoidance subscale score.

Posttraumatic Stress Disorder Scale. Age, number of traumatic events exposed to, and intensity of perceived distress associated with MI were significantly correlated with number of symptoms reported on the PSD Scale. These variables were entered into a stepwise regression analysis; however, only age was retained in the equation and accounted for $26 \%$ of the variance in symptoms reported (see Table 9).

Age, number of traumatic events exposed to, Blames Self, Avoidance, and Seeks Social Support subscales from the Ways of Coping Checklist -Revised were significantly correlated with severity of symptoms reported on the PSD Scale thus were entered into a stepwise regression analysis. Age and avoidance coping were retained in the equation and accounted for $57 \%$ of the variance in severity of symptoms reported (see Table 9). 
Table 9. Summary of Step-Wise Regression Analysis for Variables Correlating with PDS, ADIS-IV, IES, and SCL-90-R (GSI) at Follow-Up Interview.

$\underline{\text { Variable }} \quad \underline{B} \quad \underline{\text { SE B }} \underline{\text { Beta }} \underline{\text { Adj.R Square }}$ Model R Square

ADIS -IV (Number of SX; N=26)

Model 1:

$$
\text { Age } \quad-.154 \quad .043 \quad-.593 * .32
$$

Model 2

$\begin{array}{llll}\text { Age } & -.120 & .039 & -.463 * .32 \\ \text { PSS-FA } & -.354 & .123 & -.433 * .16\end{array}$

ADIS-IV (Severity of SX; N=26)

Model 1:

Age $\quad-.79 \quad .16 \quad-.71 * \quad .48$

Model 2

$\begin{array}{lcccc}\text { Age } & -.65 & .15 & -.58^{*} & .48 \\ \text { PSS-FA } & -1.21 & .47 & -.35^{*} & .10\end{array}$

IES-Intrusion; $\mathrm{N}=26$

Model 1:

Age $\quad-.36 \quad .11 \quad-.56^{*} \quad .28$

Model 2

$\begin{array}{lllll}\text { Age } & -.41 & .09 & -.64 * & .28 \\ \text { WCCL-AV } & -.72 & .20 & -.49 * & .23\end{array}$

IES-Avoidance; $\mathrm{N}=26$

Model 1:
Age
$-.3$

Model 2

$\begin{array}{lllll}\text { Age } & -.37 & .11 & -.53 * & .17 \\ \text { WCCL-AV } & -.80 & .25 & -.50 * & .22 \\ & & & & \text { Continued on next page }\end{array}$


Table 9 Continued

$\underline{\text { Variable }}$

$\underline{\text { SE B }} \underline{\text { Beta }} \underline{\text { R Square }}$

$\underline{\text { Model R Square }}$

PSD Scale Number of SX; N=26

Model 1:

Age

$\begin{array}{llll}-.19 & .05 & -.54 * \quad .26\end{array}$

PSD (Severity of Sx; N=26).

Model 1:

Age

$\begin{array}{llll}-.50 & .14 & -.59 * & .33\end{array}$

Model 2:

Age

$\begin{array}{llll}-.57 & .11 & -.67 * & .33\end{array}$

WCCL-AV

$\begin{array}{llll}-.97 & .25 & -.51 * & .24\end{array}$

SCL-90-R GSI Index; N=26

Model 1:

Number of

$-.04 \quad .01$

$.69 * \quad .36$

Trauma Events

Note. ${ }^{*} \underline{p}<.05$ 


\section{SCL 90-R/GSI Index}

Age and prior exposure to traumatic events were significantly correlated with the SCL-90-R GSI thus were entered into a stepwise regression analysis. Exposure to multiple traumas was retained in the equation and accounted for $36 \%$ of the variance in GSI scores for individuals during Phase Two (see Table 9).

\section{Discussion}

Of the forty participants completing a diagnostic interview, fifteen percent of the individuals were diagnosed with Acute Stress Disorder immediately following their MI. On the PSD, these individuals reported more re-experiencing and avoidance symptoms than individuals not meeting criteria for ASD/PTSD. Further, these individuals reported more severe reexperiencing, avoidance, and arousal symptoms than their non-ASD counterparts; however, no differences were observed on the IES between the two groups.

Approximately $30 \%$ of individuals who completed both assessment phases reported symptoms sufficient to meet criteria for PTSD at follow-up. These individuals reported significantly more re-experiencing, avoidance, and severe arousal symptoms than their non-ASD counterparts on the PSD. The PTSD group endorsed significantly more intrusion items on the IES than their non-PTSD counterparts. These individuals similarly reported higher levels of distress on all of the subscales and global indices of the SCL-90-R during Phase-Two than the non-PTSD group.

During the follow-up evaluations, only three of the individuals reporting symptoms sufficient to meet criteria for ASD post-MI continued to exhibit symptoms sufficient for a PTSD diagnosis at follow-up. Of the remaining three individuals in the ASD group during Phase One, 
two did not complete Phase Two and one individual's symptoms were not sufficient for a diagnosis of PTSD at follow-up. Thus five individuals who eventually received a PTSD diagnosis experienced subclinical symptoms during Phase One. It is quite clear from this pattern of findings that time since MI appears to be a significant factor in determining the incidence of ASD/PTSD symptoms with cardiac populations. Recently Bryant and Harvey (1998) assessed the relation between ASD and PTSD over time in a sample of motor-vehicle accident (MVA) survivors with mild traumatic brain injury. Bryant and Harvey similarly reported a higher percentage of individuals diagnosed with PTSD six months post-trauma (25\%) than individuals meeting criteria for ASD within one month post-accident (14\%). In that sample, $82 \%$ of patients with Acute Stress Disorder subsequently were diagnosed with PTSD and $11 \%$ of individuals meeting criteria for PTSD at six months did not receive an ASD diagnosis within one month of their trauma.

Due to subject attrition from Phase One to Phase Two in the present study, evolution of ASD to PTSD could not be adequately determined because two of the six individuals with ASD diagnoses during Phase One failed to complete Phase Two. It is possible they continued to meet criteria for a trauma-related disorder. The delayed onset of PTSD responses has been well documented in the literature; therefore, the five individuals with subclinical symptoms during Phase One who were later diagnosed with PTSD is not surprising. It is clear from these findings, as well as previous work, (Bryant \& Harvey, 1998) that while ASD and PTSD represent similar diagnostic categories-they do not perfectly correspond with one another. In other words, ASD does not always lead to PTSD and PTSD is not always preceded by ASD. Bryant and Harvey (1997) discussed the discrepancies between the assumption that acute stress reactions are similar and correlate with Post-Traumatic Stress Disorder and concluded that at this time there is 
insufficient research to support that the two responses are temporally and topographically the same. The uniqueness of a medical event, like MI, as a traumatic event may also result in a different pattern of ASD and PTSD symptoms than observed in samples exposed to other traumas.

The percentage of individuals experiencing ASD/PTSD symptoms immediately post-MI described in the present study approximates incidence findings reported in other post-MI samples. For example, Kutz et al. (1994) reported a 25\% incidence of PTSD following MI, and Doerfler et al. (1994) reported that $18 \%$ of their sample had scores on the Reaction Index suggestive of the presence of PTSD. However, the study by van Driel and Op den Velde (1995) reported a somewhat lower incidence finding of PTSD among cardiac patients. In that study, only 1 of 20 individuals without a prior history of trauma met criteria for PTSD within two weeks of the participant's MI. Three individuals completing their study had a prior history of trauma but no information was provided regarding these individual's responses to their MI other than their trauma symptoms from previous events had not worsened. This finding is inconsistent with Hamner (1994) who reported exacerbation of PTSD with medical illnesses. Similarly Kutz et al. (1994) reported that individuals with a previous history of PTSD were at increased risk of experiencing PTSD responses to their MI. Other studies have shown that previous trauma exposure will increase the likelihood that an individual will develop PTSD symptoms to subsequent traumatic events (cf. Steketee \& Foa, 1987; Roth, Wayland, \& Woolsey, 1990). In light of these findings, it seems likely that the three individuals with a history of trauma in the van Driel and Op den Velde (1995) study may have been at risk for experiencing new or more severe PTSD/ASD symptoms than the other participants. Lack of information regarding their response 
to their MI may have resulted in an underestimation of the incidence of PTSD/ASD in this sample. Further, individuals in this study were assessed up to two weeks post-MI (mean time interval was not reported) which represents a different time interval than the mean of four days post-MI or approximately four months post MI that was used in this study. It is possible that ASD symptoms may have remitted for some individuals who completed assessments several weeks after their MI. In fact, we observed this in one patient who met criteria for ASD in Phase One, but did not meet criteria for PTSD at Phase Two.

Additionally, a substantial number of individuals who were approached to participate in the current study did not complete the assessment protocol. It is possible that included in this non-completer group were individuals who attempted to avoid completing questionnaires which further required that the individuals recall their MI or other possible traumatic events. A study by Cohen et al. (1996) found that $57 \%$ of post-MI patients refusing to complete psychological assessments associated with their MI subsequently were referred and accepted psychological intervention by a social worker or psychologist. This finding suggests that many individuals who are acutely distressed may avoid assessments such as the questionnaire packet utilized in this study leading researchers to underestimate the number of individuals with PTSD in this sample.

The individuals reporting trauma responses sufficient to meet DSM-IV criteria in this study differed from the non-ASD/PTSD groups in many ways. ASD/PTSD patients reported more symptoms with more frequent occurrences from the re-experiencing and avoidance symptom clusters. The only non-significant difference between the two groups on the PSD was the experience of arousal symptoms during Phase One. This finding is consistent with reports from patients who endorse one or more symptoms of PTSD following various traumas such as 
robbery, physical assault, fire, motor-vehicle accidents, and other types of disasters and hazards (Norris, 1992). Experiencing of arousal symptoms appears to be common following traumatic events, even among individuals who do not go on to develop PTSD (Norris 1992). Similarly, the number of arousal symptoms was not different between the ASD and non-ASD groups during Phase One; however, the ASD group reported significantly more frequent or more severe arousal symptoms than non-ASD patients.

\section{Prediction of PTSD}

Objective and subjective variables measured during Phase One were examined regarding their relation with PTSD onset at Phase Two. For example, the variables assessing perceived distress and disability associated with the MI were significantly correlated with several ASD/PTSD measures. This is consistent with Kutz et al. (1994), who reported that anticipated incapacitation as a result of MI was significantly correlated with development of PTSD. Although Kutz et al. (1994) did not state how they assessed "anticipated incapacitation," the VAS used in this study to assess perceived distress and disability was found to be correlated with number of PTSD symptoms and to be significantly higher in the acute ASD sample in contrast to their non-ASD counterparts.

Individuals reporting more PTSD symptoms also had significantly more exposure to previous traumatic events. This findings is consistent with Kutz et al. (1994) who reported increased risk of PTSD symptoms among post-MI patients who were previously exposed to traumatic events. This is also consistent with other studies reporting a positive relation between prior trauma history and PTSD symptoms following subsequent traumatic events (cf. Steketee \& Foa, 1987; Roth, Wayland, \& Woolsey, 1990; Ullman \& Siegel, 1994). Although exposure alone 
to traumatic events does not necessitate a diagnosis of PTSD, much debate exists regarding the subjective experience of trauma versus the pure objective factor of exposure to trauma alone (cf. Bryant \& Harvey, 1997). Perhaps a cumulative effect for trauma exposure can occur, thus lowering the threshold for an individual to subsequently develop PTSD in response to a new event. Although this relation was observed in this study, it did not contribute additional variance to PTSD responses beyond that which was accounted for by age, perceived social support, and avoidant coping style. However, a previous trauma history did significantly account for $39 \%$ of the variance in the distress index on the SCL-90-R. Perhaps cumulative exposure to stress including health-related events such as MI is more helpful in predicting the subjective distress individuals experience than in measures specific to PTSD.

Subjective ratings of distress by physicians (residents) caring for these individuals significantly correlated with trauma responses reported across the various measures of trauma (i.e., ADIS-IV, IES, PSD). The distress that post-MI patients experience appears to be easily recognized by the health care providers caring for these patients; however, this recognition did not necessarily result in a formal request for a psychiatric evaluation of this problem and possible intervention. Anecdotally, the physicians providing ratings in this study stated that they perceived the level of distress observed as a normal reaction to this type of medical problem.

As this study demonstrated with this unique type of trauma, an individual's perception of a traumatic event (i.e., MI) accounted for more variance on PTSD measures than objective measures of the severity of the trauma. Congruent with Kutz et al. (1994), this study did not find significant relations between medical variables assessing actual severity of the MI and number of ASD/PTSD symptoms reported. This finding is also consistent with Trelawney-Ross \& Russell's 
(1987) finding that severity of MI was not correlated with level of anxiety and depressive symptoms reported up to six months post-MI. Similarly these authors reported that severity of physical injuries, such as those resulting from severe burns, also did not significantly account for variance on PTSD measures whereas more subjective baseline factors did. Nonetheless, inquiry into the relation between objective measures of severity and PTSD responses to MI continues to be of interest in the literature (Gross \& Kindler, 1994).

Among all previous studies assessing PTSD in cardiac populations, only Kutz et al. (1994) identified potential predictors of PTSD. Kutz et al. (1994) identified perceived disability as a result of $\mathrm{MI}$, prior MI or cardiac hospitalization, previous history of PTSD unrelated to MI, and an ethnic variable (i.e., Asian or African descent) as potential predictors of PTSD after a cardiac event. In this current study, age of the participant (pre-trauma factor) was significantly related to PTSD symptoms at follow-up across all measures of PTSD; younger patients were more likely to report trauma symptoms as a result of their MI than older patients. Further, use of avoidant coping style (post-trauma factor) accounted for a significant amount of the variance on the IES subscale scores and severity of symptoms reported on the PSD. Finally, low levels of perceived social support from family (post-trauma factor) accounted for a significant amount of variance for number and severity of symptoms during the ADIS-IV PTSD interview. Younger individuals consistently experienced more trauma responses post-MI with greater severity across all three PTSD measures than older patients. This supports the findings by Uuskula (1996) who found that younger survivors of MI require additional psychosocial intervention following first MI in comparison to older surviving patients. The possibility that a significant medical illness at an earlier age is considered less likely may also explain the higher level of trauma responses 
among younger patients. The unpredictable aspect of a sudden serious illness may contribute to this finding. The possibility of an early death and loss of physical abilities at an earlier age increases the likelihood that younger individuals will develop traumatic responses. Due to the ease with which age is obtained in comparison to other constructs investigated in this study, this variable should be of considerable utility to healthcare providers who wish to identify individuals at risk for developing psychological complications that place them at further risk for increased rates of mortality and morbidity from their heart condition.

Additionally, the more social support an individual perceived from family members appeared to serve as a buffer against more numerous and severe symptoms of PTSD but only on the ADIS-IV interview. Increased perception of social support has consistently been identified as a buffer to traumatic responses across types of trauma and against deleterious post-MI complications among cardiac patients (Friedman \& Thomas, 1995; Schaefer, Coyne, \& Lazarus, 1981). This study not only found that perceived social support was significantly related to trauma responses but that the source of the support was also significant. Perceptions of increased support from family members in contrast to friends accounted for more variance on PTSD interview indices following MI. Enhanced perception of social support has consistently been shown to have a positive influence on mortality and morbidity following medical illnesses, including MI (Berkman, Summers, \& Horowitz, 1992; Case, Moss, \& Case, 1992).

Finally, avoidant coping style was predictive of severity of symptoms reported on the PSD, IES-Intrusion, and IES Avoidance subscales. This is inconsistent with studies indicating that avoidant coping style significantly accounts for variance on PTSD measures following trauma (Bryant \& Harvey, 1995; Bryant \& Harvey, 1998) The current study observed that 
individuals who used avoidance coping tended to endorse fewer symptom responses on questionnaires, whereas those who did not use avoidant coping endorse more symptoms. This relation was not observed between avoidance coping and ADIS-IV indices of PTSD. It is possible that the inverse relation between avoidant coping and trauma responses on the questionnaires observed in this study was the result of avoidance-coping patients successfully using their avoidance-based strategies. For example, individuals with the highest avoidance scores were less likely to endorse higher occurrence of symptoms on the SCL-90-R. When examining the various subscales of the SCL-90-R, individuals with highest avoidance scores reported very little distress whereas the remaining two-thirds of the individuals with lower avoidance scores reported much higher levels of distress. This observation suggests higher endorsement of symptom occurrence among individuals with lower avoidance scores, but only on questionnaires. Presumably the reason this relation was not observed during the interview was that it is much harder to avoid or deny distress when directly questioned than when asked to complete a questionnaire.

\section{Concurrent Validation of PTSD Measures}

Finally, analyses examining the concurrent validity of the PTSD measures via the two assessment modalities (interview \& questionnaires) were examined. Significant correlations were observed across all trauma measures during Phase Two except for the relation between the IESAvoidance Scale and the overall number of symptoms reported during the ADIS-IV interview. The lack of a significant correlation between the IES-Avoidance subscale and the overall number of symptoms reported on the ADIS-IV PTSD module is not surprising. The significant correlations across all PTSD measures fell between .46 to .84 which suggests that these variables 
tap different domains of PTSD. The diagnostic domains/clusters that comprise PTSD are by definition somewhat unique and different. Comparison between overall symptom indices with the individual subscales of the IES (because there is no overall score), would predictably result in lower correlations than comparisons of two overall symptom indices (e.g., ADIS-IV and PSD overall indices). Additionally, the IES -Avoidance and Intrusion subscales are not diagnostic checklists. As such, they would be expected to correlate, but not perfectly, with PTSD diagnostic symptom domains (re-experiencing, avoidance, hyperarousal). However, the strongest correlations observed were between within scale items indicating a possible method/measure difference observed in this study. Individuals in the study may have responded differently to an interviewer assessing symptomatology versus responding to a paper and pencil assessment instrument. This may, in part, account for the lower correlations observed between PTSD measures. Additionally, the relative time between obtaining self-report and interview measures may have resulted in lower correlation coefficients. Some individuals completed the questionnaire packet prior to the interview. Other individuals completed the interview and at that time were reminded to complete and return the questionnaire packet. The follow-up contact time ranged from 15 to 46 weeks since MI across the Phase Two sample. The variable duration between these two assessments could easily result in lower correlation coefficients due to the fluctuating nature of PTSD symptoms or severity of symptoms over time.

\section{Limitations Of This Study}

Although this study attempted to overcome methodological weaknesses associated with previous studies assessing PTSD among post-MI patients, there were some limitations associated with this study. The overall sample size, for example, was somewhat small in comparison to Kutz 
et al. (1994). High subject attrition during Phase One seriously limited the number possible participants available for the follow-up evaluation. Secondly, individuals reporting exposure to more than one traumatic event (including their MI) did not complete the Phase One PTSD questionnaires with instructions to specifically respond considering their recent MI. This limited the number of dependent variables available during Phase One to measure trauma-related responses. Some individuals responded to the initial questionnaires by reporting symptoms associated with other more distressing traumatic events that had occurred prior to their MI. In contrast, ADIS-IV interviews during Phase One were conducted for PTSD/ASD responses to MI only. To permit a better assessment of PTSD symptoms during Phase Two, the questionnaire instructions were modified so that each patient was asked to answer the items in response to their recent MI; exposure to other traumatic events was assessed as well. Another limitation of this study is the lack of complete data regarding physician ratings of distress for all patients. This is particularly problematic, because this variable was significantly correlated with PTSD onset and global distress during Phase Two. The low collection rate for this variable limited our ability to extensively evaluate its unique ability to account for variance on measures of PTSD.

Another problem pertained to the fact that assessments for PTSD (questionnaire vs. interview) were administered at different time periods in a patient's recovery. Some individuals completed questionnaire packets during their hospitalization at Phase One, while others completed them after returning home. Some individuals completed interviews in the hospital but did not complete the questionnaires until they recovered from a medical procedure or felt the endurance to do so at a later time period either in the hospital or at home. Other participants completed questionnaires over several days of their hospitalization. Rarely were patients able to 
complete the interview and questionnaire packet in the same day. Finally, some individuals completed the interview, but not the questionnaires and vice versa. All of these factors likely influenced the outcomes for assessing concurrent validity of the PTSD measures and accurately assessing the transient state of ASD during Phase One. Future studies could avoid these problems by utilizing more brief questionnaires to increase compliance and quick assessment of PTSD symptoms.

Phase Two limitations are similar to those at Phase One, including, a time divergence between the two assessment modalities (interview \& questionnaires), perhaps influencing data regarding PTSD incidence and impacting data regarding concurrent validity of the PTSD measures. Secondly, the follow-up evaluations were completed without face-to-face contact which may have increased subject attrition for Phase Two and resulted in the divergence in symptoms reported across the two assessment modalities. Like Phase One, some individuals completing Phase Two did not return the questionnaires but did respond to the phone interview and vice versa.

Data regarding other possible diagnoses (e.g., mood disorders, other anxiety disorders, substance abuse disorders) via a comprehensive psychological interview were not collected for this sample. Past or concurrent treatments for psychological problems were not assessed across both Phase One and Two which may have influenced the accurate reporting of incidence. Finally, two other studies, including a treatment study for post-MI depression, were being conducted at the same time as this study and likely influenced a patient's choice to participate in this study. Significance of PTSD Symptoms Among Post-MI Individuals and Future Directions 
Psychological complications have been reported in $40-80 \%$ of patients assessed post-MI (Glassman \& Shapiro, 1998). Persistent distress has been reported in 20-30\% of samples (Byrne, \& Whyte, 1978; Cassem \& Hackett, 1971; Crowe et al., 1996; Garcia et al., 1994; Hackett \& Cassem, 1969; Lloyd \& Cawley, 1982; Naismith et al., 1979; Rosen \& Bibring, 1966; Stern et al.,1976; Wiklund et al., 1984). The nature and influence of anxiety disorders including PTSD, among post-MI patients, has been less frequently studied in comparison to other diagnoses like post-MI depression (Glassman \& Shapiro, 1998). Although morbidity, mortality, and decreased functional outcomes associated with PTSD symptoms for post-MI individuals is unknown, the long-term impact of generalized anxiety responses upon cardiac mortality has been of increasing interest (Kubzansky, Kawachi, Weiss, \& Sparrow, 1998). Kubzansky et al. (1998) recently reviewed pathophysiologic mechanisms by which anxiety may contribute to the development of CHD. Sudden increased sympathetic arousal, as seen in PTSD and ASD, is speculated to contribute to electrical instability of the myocardium, promote atherosclerotic processes, and alter cardiovascular autonomic control (Kubazansky et al., 1998). For example, anxiety at one year post-MI has been more closely associated with decreased physical functioning of the patient in comparison to severity of coronary disease at time of diagnosis (Sullivan et al., 1997). After controlling for factors associated with increased complications, Moser and Dracup (1996) reported that individuals with increased anxiety responses 48 hours after myocardial infarction have been found to be 4.9 times more likely to experience complications such as reinfarction, new onset of ischemia, ventricular fibrillation, sustained ventricular tachycardia, and in-hospital death. Similarly, Allison et al. (1995) reported that individuals reporting higher levels of anxiety had significantly higher rates of cardiovascular rehospitalization and recurrent events (including 
cardiac death, MI, SCD) within 6 months following discharge from initial hospitalization. Additionally, the acutely distressed participants had 3 to 4 times higher rehospitalization costs than non-distressed cardiac patients.

These studies highlight the significance of treating anxiety responses among post-MI individuals in both the acute and subsequent recovery periods. Although most studies of this type have examined anxiety responses, yielding a diagnosis of PTSD or ASD is quite salient in the context of a hospital environment, where various disciplines recognize the culmination of symptoms in a diagnosis as critical as the starting point for treatment decision making. The diagnostic label permits more precise communication among team members in hospital environments. Despite the importance of meeting diagnostic criterion, treatment of "subsyndromal" PTSD may also be critical for post MI patients. This is particularly true because treatment of "subsyndromal" PTSD has been shown to be effective in remission of symptoms (Blanchard, Hickling, Vollmer, \& Warren, 1995).

Others have examined the contribution of psychosocial interventions aimed at long-term health outcomes for cardiac patients (Allan \& Scheidt, 1996). A recent meta-analysis revealed that psychosocial interventions combined with standard cardiac rehabilitation components produced a $41 \%$ reduction in cardiac mortality and $48 \%$ reduction in nonfatal cardiac events (Linden, Stossel, \& Maurice, 1996). However, these programs reportedly do not adequately address distress experienced acutely that results in complication during the acute recovery phase. Elucidating the nature of anxiety responses, including PTSD, among post-MI individuals is necessary in order to identify effective interventions in the post-MI acute recovery phase. Although the specific nature of the mechanism for increased complications and mortality has not 
been specified, increased sympathetic nervous system arousal and unhealthy coping strategies (e.g., increased tobacco use) have been implicated (Fricchione \& Vlay, 1986; Kamarck \& Jennings, 1991; Niaura \& Goldstein, 1992). Identifying interventions that will effectively ameliorate or lower anxiety responses and the mechanisms that increase risk for mortality, morbidity, and decreased quality of life is an important step for future research.

Physicians caring for individual's with post-MI related anxiety disorders should be more aware of its potential occurrence and future research should attempt to delineate when appropriate intervention is warranted. Many cognitive and behavioral interventions are available for individuals with acute and chronic stress responses and could easily be employed with patients while they are still in the hospital (cf. Fairbank \& Brown, 1987). Utilization of multidisciplinary teams with a mental health professional or appropriate referral to individuals specialized in working with this population may provide opportunities for patients to be thoroughly evaluated and appropriate interventions implemented to improve quality of life and possibly decrease complications during the course of recovery from MI. 
References

Allan, R., \& Scheidt, S. (Eds.). (1996). Heart and mind: the practice of cardiac psychology. Washington D.C.: APA.

Allison, T.G., Williams, D.E., Miller, T.D., Patten, C.A., Bailey, K., Squires, R., \& Gau, G. (1995). Medical and economic costs of psychologic distress in patients with coronary artery disease. Mayo Clinic Proceedings, 70, 734-742.

Alonzo, A. \& Reynolds, N. (1998). The structure of emotions during acute myocardial infarction: a model of coping. Social Science Medicine, 46, 1099-1110.

Alter, C.L., Pelcovitz, D., Axelrod, A., Goldenberg, B., Harris, H., Meyers, B., Grobois, B., Mandel, F., Septimus, A., \& Kaplan, S. (1996). Identification of PTSD in cancer survivors. Psychosomatics, 37, 137-143.

American Heart Association. (1989). Heart Facts. Dallas: American Heart Association. American Psychiatric Association. (1980). Diagnostic and statistical manual of mental disorders. (3rd ed.). Washington, DC: Author.

American Psychiatric Association. (1987). Diagnostic and statistical manual of mental disorders. (3rd ed. revised). Washington, DC: Author.

American Psychiatric Association. (1994). Diagnostic and statistical manual of mental disorders. (4th ed.). Washington, DC. Author.

Andrykowski, M., Cordova, M., Duhamel, K., \& Manne, S. (1998). Posttraumatic stress disorder associated with cancer diagnosis and treatment [Abstract]. Annals of Behavioral Medicine, 20, S024. 
Arntz, A., Merckelbach, H., \& de Jon, P. (1993). Opiod antagonist affects behavioral effects of exposure in vivo. Journal of Consulting and Clinical Psychology, 61, 865-870.

Atkeson, B.M., Calhoun, K.S., Resick, P.A., \& Ellis, E.M. (1982). Victims of rape: repeated assessment of depressive symptoms. Journal of Consulting and Clinical Psychology, 50, 96-102.

Berkman, L.F., Summers, L., \& Horwitz, R. (1992). Emotional support and survival after myocardial infarction: a prospective, population based study of the elderly. Annals of Internal Medicine, 117, 1003-1009.

Bouman, T.K., \& de Ruiter, C. (1991). The validity of the anxiety disorders interview schedule-revised (ADIS-R): a pilot study. Gedragstherapie, 24, 77-88.

Breslau, N., Davis, G., Andreski, P., \& Peterson, E. (1991). Traumatic events and posttraumatic stress disorder in an urban population of young adults. Archives of General Psychiatry, 48, 216-222.

Brezinka, V., \& Kittel, F. (1995). Psychosocial factors of coronary heart disease in women: a review. Social Science Medicine, 42, 1351-1365.

Brown, T., Di Nardo, P., \& Barlow, D. (1994). Anxiety Disorders Interview Schedule for DSM-IV (ADIS-IV): Manual. Albany: Graywind.

Brown, A. \& Finkelhor, D. (1986). Impact of child sexual abuse: a review of the research. Psychological Bulletin, 99, 66-77.

Brown, M.A., \& Munford, A. (1984). Rehabilitation of post MI depression and psychological invalidism: A pilot study. International Journal of Psychiatry and Medicine, 13(4), 291-298. 
Burgess, A.W., \& Holmstrum, L.L. (1974). Rape: Victims of Crisis. Bowie, MD: Robert J. Brady.

Butler, R.W., Rizzi, L.P., \& Handwerger, B.A. (1996). The assessment of posttraumatic stress disorder in pediatric cancer patients and survivors. Journal of Pediatric Psychology, 21(4), 499-504.

Byrne, D.G., \& Whyte, H.M. (1978). Dimensions of illness behavior in survivors of myocardial infarction. Journal of Psychosomatic Research, 22: 485-491.

Bryant, R.A., \& Harvey, A.G. (1995). Avoidant coping style and post-traumatic stress following motor vehicle accidents. Behaviour Research and Therapy, 33, 631-635.

Bryant, R.A., \& Harvey, A.G. (1997). Acute stress disorder: a critical review of diagnostic issues. Clinical Psychology Review, 17, 757-773.

Bryant, R.A., \& Harvey, A.G. (1998). Relationship between acute stress disorder and posttraumatic stress disorder following mild traumatic brain injury. American Journal of Psychiatry, 155, 625-629.

Case, R., Moss, A., \& Case, N. (1992). Living alone after myocardial infarction: impact on prognosis. Journal of the American Medical Association, 267, 515-519.

Cassem, N.H., \& Hackett, T.P. (1971). Psychiatric consultation in a coronary care unit. Annals of Internal Medicine, 75, 9-14.

Cay, E.L., Vetter, N.J., Philip, A.E., \& Dugard, P. (1973). Return to work after a heart attack. Journal of Psychosomatic Research, 16, 231-243. 
Cohen, L., Stokhof, L.H., \& van der Ploeg, H.M. (1996). Identifying patients recoverying from a recent myocardial infarction who require and accept psychological care. Psychological Reports, 79, 1371-1377.

Cordova, M.J., Andrykowski, M.A., Kenady, D.E., McGrath, P.C., Sload, D.A., \& Redd, W.H. (1995). Frequency and correlates of posttraumatic-stress-disorder-like symptoms after treatment for breast cancer. Journal of Consulting and Clinical Psychology, (63), 981-986.

Cordova, M.J., Studts, J.L., \& Andrykowski, M.A. (1998). Posttraumatic stress disorder following breast cancer [Abstract]. Annals of Behavioral Medicine, 20, S024.

Crowe, J.M., Runions, J., Ebbesen, L., Odridge, N., \& Streiner, D. (1996). Anxiety and depression after acute myocardial infarction. Heart and Lung, 25, 98-107.

Derogatis, L. (1977). Symptom Checklist - 90 - R: Administration, Scoring and Procedures Manual -II For the Revised Version. Tisane: Clinical Psychometric Research.

Derogatis, L.R., Lipman, R.S., \& Covi, L. (1973). SCL-90: an outpatient psychiatric rating scale-preliminary report. Psychopharmacology Bulletin, 7, 13-28.

Di Nardo, P., Moras, K., Barlow, D.H., \& Rapee, R.M. (1993). Reliability of the DSMIII-R anxiety disorder categories: using the anxiety disorders interview schedule-revised (ADISR). Archives of General Psychiatry, 50, 251-256.

Di Nardo, P., O'Brien, G., Barlow, D., Waddell, M., \& Blanchard, E. (1983). Reliability of DSM-III anxiety disorders categories using a new structured interview. Archives of General Psychiatry, 40, 1070-1074. 
Doerfler, L.A., Pbert, L., \& DeCosimo, D. (1994). Symptoms of Posttraumatic Stress disorder following myocardial infarction and coronary artery bypass surgery. General Hospital Psychiatry, 16, 193-199.

Duhamel, K., Vickburg, S., Smith, M., \& Papadopoulous, E. (1998). PTSD as a model for understanding adjustment problems in bone marrow transplant survivors [Abstract]. Annals of Behavioral Medicine, 20, S024.

Fairbank, J.A., \& Brown, T.A. (1987). Current behavioral approaches to the treatment of posttraumatic stress disorder. Behavior Therapist, 10, 57-64.

Fairbank, J.A., Schlenger, W.E., Caddell, J.M. \& Woods, M.G. (1993). Post-Traumatic Stress Disorder. In, Sutker, P., \& Adams, H., (Eds.), Comprehensive Handbook of Psychopathology, 2nd Edition, Plenum Press: New York.

Feinstein, A., \& Dolan, R. (1991). Predictors of post-traumatic stress disorder following physical trauma: an examination of the stressor criterion. Psychological Medicine, 21, 85-91.

Feldham, R. (1986). Self-esteem, types of attributional style and sensation and distress pain ratings in males. Journal of Advanced Nursing, 11, 75-86.

Foa, E. (1995). Posttraumatic Stress Diagnostic Scale Manual. Minneapolis: National Computer Systems.

Foy, D.W., Resnick, H.S., Sipprelle, R.C., \& Carroll, E.M. (1987). Premilitary, military, and postmilitary factors in the development of combat-related posttraumatic stress disorder. Behavior Therapist, 10, 3-9. 
Foy, D., Sipprelle, R., Rueger, D., \& Carroll, E. (1984). Etiology of Posttraumatic stress disorder in vietnam veterans: analysis of premilitary, military, and combat exposure influences. Journal of Consulting and Clinical Psychology, 52, (1), 79-87.

Frasure-Smith, N. (1991). In hospital symptoms of psychological stress as predictors of long-term outcome after acute myocardial infarction in men. American Journal of Cardiology, 67. 121-127.

Frasure-Smith, N., Lesperance, F., \& Talajic, M. (1993). Depression following myocardial infarction: impact on 6-month survival. Journal of the American Medical Association, 270, $1819-1825$.

Frasure-Smith, N., Lesperance, F., \& Talajic, M. (1995). The impact of negative emotions on prognosis following myocardial infarction: is it more than depression. $\underline{\text { Health }}$ Psychology, 14, 388-398.

Frederick, C.J. (1985). Selected foci in the spectrum of posttraumatic stress disorders. In J. Laube \& S. Murphy's (Eds.) Perspectives in Disaster Recovery, Norwalk: Appleton-CenturyCrofts.

Fricchione, G., \& Vlay, S. (1986). Psychiatric aspects of patients with malignant ventricular arrhythmias. American Journal of Psychiatry, 343, 1518-1526.

Friedmann, E., \& Thomas, S. (1995). Pet ownership, social support, and one year survival after acute myocardial infarction in the cardiac arrhythmia suppression trial (CAST). American Journal of Cardiology, 76, 1213-1217. 
Garcia, L., Valdes, M., Jodar, I., Riesco, N., \& Flores, T. (1994). Psychological factors and vulnerability to psychiatric morbidity after myocardial infarction. Psychotherapy and Psychosomatics, 61, 187-194.

Garrity, T.F. (1973). Social involvement and activeness as predictors of morale six months after first myocardial infarction. Social Science \& Medicine, 7, 99-107.

Glassman, A.H., \& Shapiro, P. (1998). Depression and coronary artery disease. American Journal of Psychiatry, 155, 4-11.

Golding, J.M., Siegel, J.M., Sorenson, S.B., Burnam, M.A., \& Stein, J.A. (1989). Social support sources following sexual assault. Journal of Community Psychology, 17, 92-107.

Green, B., Grace, M.C., Lindy, J.D., Gleser, G.C., Leonard, A.C., \& Kramer, T.L. (1990). Buffalo creek survivors in the second decade: Comparison with unexposed and nonlitigant groups. Journal of Applied Social Psychology, 20, 1033-1050.

Gross, R. \& Kindler, S. (1994). Occurrence of high levels of posttraumatic stress disorder symptom in patient who had survived a myocardial infarction or coronary artery bypass graft surgery . General Hospital Psychiatry, 16, 56-57.

Hackett, T.P., \& Cassem, N.H. (1969). Detection and treatment of anxiety in the coronary care unity. American Heart Journal, 78, 727-730.

Hackett, T.P., \& Cassem, N.H. (1982). Coping with cardiac disease. $\underline{\text { Advances in }}$ Cardiology, 31, 212-217.

Hamner, M.B. (1994). Exacerbation of posttraumatic stress disorder with medical illness. General Hospital Psychiatry, 16, 135-137. 
Harvey, A.G., \& Bryant, R.A. (1997). Predictors of acute stress following mild traumatic brain injury. Brain Injury, 12, 147-154.

Helzer, J., Robins, L., \& McEvoy, L. (1987). Post-traumatic stress disorder in the general population: Findings of the Epidemiologic Catchment Area Survey. New England Journal of Medicine, 317, 1630-1634.

Holmes, S. (1989). Use of a modified symptom distress scale in assessment of the cancer patient. International Journal of Nursing Studies, 26, 69-79.

Horowitz, M., Wilner, N., \& Alvarez, W. (1979). Impact of event scale: a measure of subjective stress. Psychosomatic Medicine, 41, 209-218.

Joseph, S.A., Andrews, B., Williams, R., \& Yule, W. (1992). Crisis support and psychiatric symptomatology in adult survivors of the Jupiter cruise ship disaster. British Journal of Clinical Psychology, 31, 63-73.

Kamarck, T., \& Jennings, J. (1991). Biobehavioral factors in sudden cardiac death. Psychological Bulletin, 109, 42-75.

Kaniasty, K., \& Norris, F.H. (1992). social support and victims of crime: Matching event, support, and outcome. American Journal of Community Psychology, 20, 211-241.

Kannal, W.B., \& Abbott, R.D. (1984). Incidence and prognosis of unrecognized myocardial infarction. An update on the Framingham Study. The New England Journal of Medicine, 311, 1144-1148.

Kilpatrick, D., \& Resnick, H. (1992). PTSD associated with exposure to criminal victimization in clinical and community populations. In J. Davidson \& E. Foa (EDS.). Post- 
traumatic stress disorder in review: Recent research and future directions. Washington, DC: American Psychiatric Press.

Kilpatrick, D.G., Saunders, B.E., Amick-McMullan, A., Best, C.L., Veronen, L.J., \& Resnick, H.S. (1989). Victim and crime factors associated with the development of crime-related post-traumatic stress disorder. Behavior Therapy, 20, 199-214.

Kilpatrick, D.G., Saunders, B.E., Veronen, L.J., Best, C.L., \& Von, J.M. (1987). Criminal victimization: Lifetime prevalence, reporting to police, and psychological impact. Crime and Delinquency, 33, 479-489.

Kilpatrick, D.G., Veronen, L.J., \& Best, C.L. (1985). Factors predicting psychological distress among rape victims. In C.R. Figley (Ed.), Trauma and Its Wake (pp. 113-141). New York: Brunner/Mazel.

Kowey, P. (1988). The calamity of cardioversion of conscious patients. The American Journal of Cardiology, 61, 1106-1107.

Kubzansky, L., Kawachi, I., Weiss, S. \& Sparrow, D. (1998). Anxiety and coronary heart disease: A synethesis of epidemiological, psychological, and experimental evidence. Annals of Behavioral Medicine, 20, 47-58.

Kulka, R., Schlenger, W., Fairbank, J., Hough, R., Jordan, C., Marmar, C., \& Weiss, D. (1988). National Vietnam veterans readjustment study (NVVRS): Description, current status, and initial PTSD prevalence estimates. Washington, DC: Veterans Administration.

Kutz, I., Garb, R., \& David, D. (1988). Post-traumatic stress disorder following myocardial infarction. General Hospital Psychiatry, 10, 169-176. 
Kutz, I., Shabtai, H., Solomon, Z., Neumann, M. \& David, D. (1994). Post-traumatic stress disorder in myocardial infarction patients: Prevalence study. Israeli Journal of Psychiatry Related Sciences, 31(1), 48-56.

Linden, W., Stossel, C., \& Maurice, J. (1996). Psychosocial interventions for patients with coronary artery disease: a meta-analysis. Archives of Internal Medicine, 156, 745-752.

Lloyd, G.G. \& Cawley, R.H. (1982). Psychiatric morbidity after myocardial infarction. Quarterly Journal of Medicine, 201, 33-42.

Manne, S.L., Galleli, K., DuHamel, K., \& Vickberg, S. (1998). Diagnosis of ptsd among parents of pediatric bone marrow transplant survivors using the structured clinical interview for DSM-IV [Abstract]. Annals of Behavioral Medicine, 20, S024.

Mednick, V., Baker, R., \& Carothers, L. (1990). Patterns of family instability and crime: the association of timing of the family's disruption with subsequent adolescent and young adult criminality. Journal of Youth and Adolescence, 19(3), 201-220.

McCahill, T., Meyer, L., \& Fischman, A.M. (1979). The Aftermath of Rape. Lexington, MA: C.C. Heath.

Mayou, R. (1984). Prediction of emotional and social outcome after a heart attack. Journal of Psychosomatic Research, 28, 17-25.

Moser, D.K., \& Dracup, K. (1996). Is anxiety early after myocardial infarction associated with subsequent ischemic and arrhythmic events? Psychosomatic Medicine, 58, 395-401.

Naismith, L.D., Robinson, J.F., Shaw, G.B., \& McIntyre, M.M.J. (1979). Psychological rehabilitation after myocardial infarction. British Medical Journal, 1, 439-446. 
Neumann, J.K. (1991). Psychological post-traumatic effects of MI: A comparison study. Medical Psychotherapy, 4 105-110.

Niaura, R., \& Goldstein, M. (1992). Psychological factors affecting physical condition: cardiovascular disease literature review. Psychosomatics, 33, 146-155.

Norris, F.H. (1992). Epidemiology of trauma: Frequency and impact of different potentially traumatic events on different demographic groups. Journal of Consulting and Clinical Psychology, 60, 409-418.

Perry, S., Difede, J., Musngi, G., Frances, A. \& Jacobsberg, L. (1992). Predictors of posttraumatic stress disorder after burn injury. American Journal of Psychiatry, 149, 931-935.

Procidano, M.., \& Heller, K. (1983). Measures of perceived social support from friends and from family: Three validation studies. American Journal of Community Psychology, 11, 124.

Ridley, J. (1991). A conceptual and theoretical model for PTSD in vietnam veterans, rape $\underline{\text { survivors, and child incest victims. Unpublished manuscript. }}$

Roberts, R., Morris, D., Pratt, C., \& Alexander, R. (1994). Pathophysiology, recognition, and treatment of acute myocardial infarction and its complications. In R.C. Schlant \& R. Alexander (Eds.), Hurst's The Heart (1107-1184). New York: McGraw-Hill.

Rosen, J.L., \& Bibring, G.L. (1966). Psychological reactions of hospitalized male patients to a heart attack - age and social class differences. Psychosomatic Medicine, 28(6), 808-821.

Roth, S., Wayland, K., \& Woolsey, M. (1990). Victimization history and victim-assailant relationship as factors in recovery from sexual assault. Journal of Traumatic Stress, 3 , 169-180. 
Sanne, H. (1986). Rehabilitation after a myocardial infarction. Acta Medica of Scandinavia Supplement, 712, 72-76.

Schaefer, C., Coyne, J., \& Lazarus, R. (1981). The health-related functions of social support. Journal of Behavioral Medicine, 4, 381-405.

Schleifer, S.J., Macari-Hinson, M.M., \& Coyle, D.A. (1989). The nature and source of depression following myocardial infarction. Archives of Internal Medicine, 149, 1785-1789.

Schwarzwald, J., Solomon, Z., Weisenber, M., \& Mikulincer, M. (1987). Validation of the impact of event scale for psychological sequelae of combat. Journal of Consulting and Clinical Psychology, 55, 251-256.

Scotti, J., Beach, B.K., Northrop, L.M.E., Rode, C., \& Forsyth, J.P. (1995). The psychological impact of accidental injury: a conceptual model for clinicians and researchers. In John R. Freedy \& S.E. Hobfoll (Eds.) Traumatic Stress: From Theory (181-211). New York: Plenum Press.

Settles, B. (1993). The illusion of stability in family life: the reality of change and mobility. Marriage and Family Review, 19(1-2), 5-29.

Shalev, A.Y., Schreiber, S., \& Galai, T. (1993). Post-traumatic stress disorder following medical events. British Journal of Clinical Psychology, 32, 247-253.

Shore, J.H., Tatum, E.L., \& Vollmer, W.M. (1986). Evaluation of mental health effects of disaster, Mount St. Helens eruption. American Journal of Public Health, 76(Supp.), 76-83.

Smith, T.W., \& Leon, A.S. (1992). Coronary Heart Disease: A Behavioral Perspective. Champaign: Research Press. 
Smith, E.M., North, C.S., McCool, R.E., \& Shea, J.M. (1990). Acute postdisaster psychiatric disorders: Identification of persons at risk. American Journal of Psychiatry, 147, 202206.

Solomon. Z. (1989). A three year prospective study of post traumatic stress disorder in Israeli combat veterans. Journal of Traumatic Stress, 2, 59-73.

Solomon, Z. Mikulincer, M., \& Avitzur, E. (1986). Coping, locus of control, social support, and combat-related posttraumatic stress disorder: a prospective study. Journal of Personality and Social Psychology, 2, 279-285.

Solomon, Z., Mikulincer, M., \& Jacob, B.R. (1987). Exposure for recurrent combat stress: combat stress reactions among Israeli soldiers in the 1982 Lebanon war. Psychological Medicine, 17, 433-440.

Spielberger, C., Gorsuch, R., Lushene, R., Vagg, P., Jacobs, G. (1983). Manual for the State-Trait Anxiety Inventory (Form Y). Palo Alto, CA, Consulting Psychologists Press.

Spitzer, R.L., \& Williams, J. (1985). Instruction Manual for the Structured Clinical Interview for DSM-III (SCID). New York: Biometrics Research.

Steketee, G., \& Foa, E.B. (1987). Rape victims: Post-traumatic stress responses and their treatment: a review of the literature. Journal of Anxiety Disorders, 1, 69-86.

Stern, M.J., Pascale, L., \& McLoone, J.B. (1976). Psychosocial adaptation following an acute myocardial infarction. Journal of Chronic Disease, 29, 513-526.

Sullivan, M.D., LaCroix, A.Z., Baum, C., Grothaus, L., \& Katon, W. (1997). Functional status in coronary artery disease: a one-year prospective study of the role of anxiety and depression. The American Journal of Medicine, 103, 348-356. 
Thomas, R.J, McEwen, J., \& Asbury, A. (1996). The Glasgow Pain Questionnaire: A new generic measure of pain, development and testing. International Journal of Epidemiology, $\underline{25}, 1060-1067$.

Thompson, D.R., Webster, R.A., Cordle, C.J., \& Sutton, T.W. (1987). Specific sources and patterns of anxiety in male patients with first myocardial infarction. British Journal of Medical Psychology, 60, 343-348.

Trelawny-Ross, C., \& Russell, O. (1987). Social and psychological responses to myocardial infarction: Multiple determinants of outcome at six months. Journal of Psychosomatic Research, 31(1), 125-130.

Ullman, S.E., \& Siegel, J.M. (1994). Predictors of exposure to traumatic events and posttraumatic sequelae. Journal of Community Psychology, 22, 328-338.

Uuskula, M. (1996). Psychological differences between young female and male survivors of myocardial infarction. Psychotherapy and Psychosomatics, 65, 327-330.

van Driel, R.C., \& Op den Velde, W. (1995). Myocardial infarction and post-traumatic stress disorder. Journal of Traumatic Stress, 8, 151-159.

Vitaliano, P.P., Russo, J., Carr, J.E., Majuro, R.D., \& Becker, J. (1985). The ways of coping checklist: Revision and psychometric properties. Multivariate Behavioral Research, 20, 326.

Vogt, T., Pope, C., Mullooly, J., \& Hollis, J. (1994). Mental health status as a predictor of morbidity and mortality: A 15-year follow-up of members of a health maintenance organization. American Journal of Public Health, 84, 227-231. 
Weismman, M.,. \& Bothwell, S. (1976). The assessment of social adjustment by patient self-report. Archives of General Psychiatry, 33, 1111-1115.

Wenger, N.K. (1994). Rehabilitation of the patient with coronary heart disease. In R.C. Schlant \& R. Alexander (Eds.), Hurst's The Heart (1223-1237). New York: McGraw-Hill.

Wiklund, I., Sanne, H., Elmfeldt, D., Vedin, E., \& Wilhelmsson, C. (1984). Emotional reaction, health preoccupation and sexual activity two months after myocardial infarction.

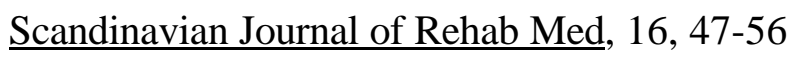

Wiklund, I. Sanne, H., Vedein, A., \& Wilhelmsson, C. (1984b). Sick-role and attitude towards disease and working life two months after a myocardial infarction. Scandinavian Journal of Rehabilitation Med, 16, 57-64.

Wiklund, I., Sanne, H., Vedin, A., \& Wilhelmsson, G. (1984). Psychosocial outcome one year after a first myocardial infarction. Journal of Psychosomatic Research, 28(4), 309-321.

Winfield, I., George, L.K., Swartz, M., \& Blazer, D.G. (1990). Sexual assault and psychiatric disorders among a community sample of women. American Journal of Psychiatry, $147,335-341$.

Wirtz, P.W., \& Harrell, A.V. (1987). Effects of postassault exposure to attack-similar stimuli on long-term recovery of victims. Journal of Consulting and Clinical Psychology, 55, 1016.

Wolfe, V.V., Gentile, C., \& Wolfe, D.A. (1989). The impact of sexual abuse on children: a PTSD formulation. Behavior Therapy, 20, 215-228. 
Zimmerman, M., \& Coryell, W. (1987). The inventory to diagnose depression (IDD): a self-report scale to diagnose major depressive disorder. $\underline{\text { Journal of Consulting and Clinical }}$ Psychology, 55, 55-59.

Zimmerman, M., Coryell, W., Corenthal, C., \& Wilson, S. (1986). A self-report scale to diagnose major depressive disorder. Archives of General Psychiatry, 43, 1076-1081. 
Appendix A

Curriculum Vitae 


\section{CURRICULUM VITAE}

\section{IDENTIFYING INFORMATION}
NAME:
Risa Nakase Thompson
BORN:
January 11, 1971 in Akashi City, Japan
NATIONALITY:
U.S. Citizen
ADDRESS:
Mississippi Methodist Rehabilitation Center Neuropsychology Department
1350 East Woodrow Wilson
Jackson, MS 39216
PHONE:
Office:
Home:
(601) $364-3411$
FAX:
E-mail: nakase@aol.com
(601) 939-5344
(601) 364-33057
EDUCATION
1998-Present
Post-Doctoral Neuropsychology Fellow, Neuropsychology Department, Mississippi Methodist Rehabilitation Center, Jackson, MS
1997-1998
Behavioral Medicine Psychology Resident, Department of Psychiatry \& Human Behavior, University of Mississippi Medical Center \& Jackson VAMC Consortium, Jackson, MS
1993-1999
Ph.D., Department of Psychology, West Virginia University, Morgantown, WV. Dissertation: Medical and Psychological Predictors of PTSD Symptoms Following Myocardial Infarction, Chair: Kevin Larkin, Ph.D. Committee Members: Barry Edelstein, Ph.D., Stanley Cohen, Ph.D., Joseph Scotti, Ph.D., \& Stanley Schmidt, M.D.
1996
M.A., Masters Degree in Clinical Psychology, West Virginia University, Morgantown, W.V.
1993
B.S., Magna Cum Laude, Psychology, Mississippi College, Clinton, MS
H.S. Diploma, High Honors, Biloxi High School, Biloxi, MS 
HONORS AND AWARDS

1993

1993

1993

1992

1992

1992

1992

1992

1992

1990

1989-1993
HERF Award, West Virginia University

Perry Academic Award, Mississippi College

Senior Psychology Award, Mississippi College

Psi Chi Outstanding Junior in Psychology Award

Who's Who Among Students in American Universities

Psi Chi, National Psychology Honor Society, President of the Mississippi College Chapter

Mortar Board, National Honor Society, President of the Mississippi College Chapter

Alpha Chi, National Academic Honor Society

Omicron Delta Kappa, National Honor Society

Freshman Woman of the Year, Mississippi College

Mississippi College Honors Scholarship

\section{TEACHING EXPERIENCE}

1996-1997

Fall, 1996

Spring,1996

1996

1993

1995
T.A., Department of Psychology, West Virginia University, Morgantown, WV. Supervisor: Tracy Morris, Ph.D.

Guest Lecture, Department of Psychology, WVU, Morgantown, WV. Course Supervisor: Barry Edelstein, Ph.D.

T.A., Department of Psychology \& School of Dentistry, WVU Morgantown, WV. Course Supervisor: Daniel McNeil, Ph.D.

T.A., Department of Psychology, WVU. Morgantown, WV. Course Supervisor: Tracy Morris, Ph.D.

T. A., Department of Psychology, WVU. Morgantown, WV. Course Supervisor: John Crosby, Ph.D.

T.A. , Department of Psychology, WVU. Morgantown, WV. 
RESEARCH EXPERIENCE

1998-Present

1997-Present

1997-Present

1995-1997

1996-1997

1996-1998
TBI Model Systems of Mississippi, Mississippi Methodist Rehabilitation Center, Jackson, MS.

Duties: 1) Serve as the Data Collection Manager for the Traumatic Brain Injury Model Systems of Mississippi, NIDRR Grant at MMRC.

Cognitive Clinic, Behavioral Education and Consultation Service, Jackson VAMC, Jackson, MS. Supervisor: Phil Godding, Ph.D.

Duties: 1) Establishing database for cognitive and neuropsychological assessments conducted by the service, 2) Data-entry and analyses for study investigating normative profiles on the Cognitive Capacity Screening Examination across various clinical samples (i.e., dementia, general medical, substance abuse, cancer, and psychiatric) and concurrent validity with the Dementia Rating Scale, 3) Data-entry and writing responsibilities for a structural equation analysis of the Wechsler Memory ScaleRevised, California Verbal Learning Test, and Rey Auditory Verbal Learning Test.

Health Behavior Program, Jackson VAMC, Jackson, MS. Supervisor: Thomas Payne, Ph.D.

Duties: 1)Data entry and assistance with analyses of study investigating cued psychophysiological responses to smoking, 2)Data-entry for study investigating effects of cognitive-behavioral smoking cessation intervention.

Cardiology Service, Department of Medicine, West Virginia University Hospitals, Morgantown, WV. Supervisor: Kevin Larkin, Ph.D, Anthony Morise, M.D., \& David Beckner, M.D.

Duties: Designing methodology and coordinating data collection for a study investigating gender differences in presentation of coronary artery disease and for a study investigating psychological responses to the implantable cardioverter defibrillator.

Physician's Office Center, Morgantown, WV. Supervisor: Kevin Larkin, Ph.D.

Duties: Data collection on daily stress and ambulatory blood pressure in individuals with essential hypertension.

Forensics Research Group, Department of Psychology, WVU. Morgantown, WV. Supervisor: Bill Fremouw, Ph.D, ABPP

Duties: Methodological development and data-analysis of 1) Study investigating the impact of Stalking on Victims, and 2) Study investigating attachment styles in acquaintance stalking relationships compared to non-stalking relationships.

Center for Anxiety Disorders, West Virginia University Morgantown, WV. Supervisor: Georg H. Eifert, Ph.D. 
Duties: 1)Assisted with the set-up and data collection of a study measuring conditioned panic responses via physiological and selfreport methods to video presentations of interoceptive and exteroceptive stimuli, 2) Collected data in the WVUH Pain Clinic at the Physicians Office Center for a study examining the influence of trait anxiety and depression's effect on chronic pain patient's coping methods and pain responses, 3) Revised and validated the Cardiac Anxiety Questionnaire on a sample of patients referred for cardiac catheterization at Ruby Memorial Hospital.

1993-1995

Post-Traumatic Stress Disorder Research Group, West Virginia University, Morgantown, WV. Supervisor: Joseph Scotti, Ph.D.

Duties: Data entry for a study examining the impact of the Gulf War on veterans, their spouses and children, 2) literature review for and editing of a chapter examining the impact of accidental injury on behavioral health.

1992-93

Trauma Recovery Program, Veteran's Affairs Medical Center, Jackson, MS. Supervisors: Judith Lyons, Ph.D. and Patrick Smith, Ph.D.

Duties: Reviewed the literature and assisted in designing a study investigating cue-induced analgesia in Vietnam Veterans with Post Traumatic Stress Disorder, 2) Edited heart rate data for a study investigating the effects of various stressors on physiological responses in Veterans with Post Traumatic Stress Disorder.

1991-93

Honors Program, Mississippi College, Clinton, MS. Supervisor: Gloria Fisher, Ph.D.

Duties: Designed and implemented a study investigating the PathGoal Theory of Leadership. Assessed how locus of control moderated predicted relationships between leader initiating structure and subordinate satisfaction.

1992

Psychology Service, Veteran's Affairs Medical Center, Biloxi, MS. Supervisors: Kenneth R. Jones, Ph.D. and Steven McNally, Ph.D.

Duties: 1) Administered questionnaires investigating critical incidents in health care provider responses to the needs of patients with chronic illnesses, 2) Administered structured interviews to patients for a study investigating the prevalence of substance abuse among male substance abusers.

1992

Semko and Associates, Jackson, MS. Supervisor: Gloria Fisher, Ph.D.

Duties: Conducted literature reviews of legal cases for the development of a test to measure hostile-interpersonal environments. 


\section{CLINICAL EXPERIENCE}

1998-

1997-1998

(11/97-2/98):

1995-1997
Neuropsychology Fellow, Mississippi Methodist Rehabilitation Center (MMRC) \& University of Mississippi Medical Center (UMMC), Jackson, MS

MMRC: Neuropsychological assessment and management of adult and adolescent inpatient and outpatients referred following traumatic brain injury, stroke, tumor resection, and spinal cord injury.

UMMC: Neuropsychological assessment of adult and pediatric inpatient and outpatients referred following traumatic brain injury, stroke, epilepsy surgery, and chemical poisoning.

\section{Psychology Resident, University of Mississippi Medical Center \&} Jackson VAMC Consortium, Jackson, MS.

Behavioral Education and Consultation Rotation (BE\&C), Supervisor: Phil Godding, Ph.D. (8/97-11/97): Neuropsychological, personality, competency, malingering, anxiety, depression, and cognitive assessments for medical inpatients, medical outpatients, and compensation and pension claimants. Other duties include consultation to oncology/radiation therapy, primary care clinics, and comprehensive pain management clinic. Finally, co-leader of 6 -week chronic pain management group utilizing cognitive-behavioral and educational interventions.

Health Behavior Program, Supervisor: Thomas Payne, Ph.D.

Assessment and treatment of inpatients and outpatients presenting with cardiovascular risk factors and other stress-related medical disorders via a cardiac and smoking cessation clinic. Participation on cardiac rehabilitation team and consultation to primary care clinics.

Joint Rotation: Chemical Dependency Treatment Program (CDTP)Supervisors: James Fitterling, Ph.D. or Jefferson Parker, Ph.D., and Clinical Neuropsychology, Supervisor: Bradley Burton, Ph.D. (2/98 - 5/98): CDTP: Individual and group behavioral treatment of psychoactive substance use disorders and concomitant psychosocial problems via inpatient residential and outpatient rehabilitation programs.

Neuropsychology (see below)

Clinical Neuropsychology, Supervisors: D. Bradley Burton, Ph.D. \& Mark Sherer, Ph.D.(5/98-8/98):

Neuropsychological evaluation of neurologically and psychiatrically impaired individuals, instituting cognitive rehabilitation programs, consultation to multi-disciplinary teams, and developing intervention programs for neurologically impaired individuals.

Section of Cardiology, Department of Medicine, West Virginia University Hospital, Morgantown, WV. Supervisor: Kevin Larkin, Ph.D. \& David Beckner, M.D. 
Duties: Psychological assessment of cardiac patients receiving an implantable cardioverter defibrillator (ICD) and/or pacemaker. Administration of psychological component of ICD support group. Bedside assessment and brief intervention for individuals with psychological factors complicating medical condition or atypical chest pain during cardiology rounds.

1996-1997

Vertical Team, Quin Curtis Center, WVU, Morgantown, WV. Supervisor: Kevin Larkin, Ph.D.

Duties: Individualized assessment and treatment of patients with anxiety and depression referred from Section of Cardiology, Department of Medicine.

1995-96

Practicum Student, Sharpe Hospital and Summit Center, West Virginia. Supervisors: Barry Edelstein, Ph.D., Mike Todt, Ph.D., Peggy Allman, M.A. \& Paul Macom, M.A.

Duties: Implement relapse prevention group in day treatment program at $\mathrm{CMHC}$, write behavioral plans, and evaluate treatment plans for recidivists in day treatment program. Program evaluation of continuity of care between inpatient psychiatric setting to community mental health center placement and treatment.

1994-95

Practicum Student, Carruth Center for Counseling and Psychological Services, Morgantown, WV. Director of Training: Scott Friedman, Psy.D. Supervisor: Phil Comer, Ph.D.

Duties: Provided individual and group treatment for undergraduate and graduate students as well as individual psychological assessment at West Virginia University.

1994-95

Vertical Team, Quin Curtis Center, WVU, Morgantown, WV. Supervisor: Georg H. Eifert, Ph.D.

Duties: Individualized assessment and treatment.

1992

Psychology Apprentice, Veteran's Affairs Medical Center, Biloxi and Gulfport, MS. Director of Training: Kenneth R. Jones, Ph.D. (400 hours)

Duties in Biloxi: Assisted in the assessment of patients in the Walkin Clinic of Behavioral Medicine and conducted Reminiscence Therapy in the Nursing Home Care Unit.

Duties in Gulfport: Received training and administered Mental Status Examinations on the Admissions Ward of an in-patient unit.

\section{PROFESSIONAL AFFILIATIONS}

International Association of Neuropsychology

National Association of Neuropsychology

American Psychological Association

Division for Clinical Psychology, APA

American Psychological Association of Graduate Students

Association for the Advancement of Behavior Therapy

Disaster and Trauma SIG of AABT

Society for Behavioral Medicine 


\section{PUBLICATIONS}

Thompson, R., Brown, S., Beach, B., \& Beeler, B. (1994). The hidden victim. Disaster and Trauma Currents, 3, 5-6.

Forsyth, J.P., Eifert, G.H., \& Thompson, R.N. (1996). Systemic alarms in fear conditioning II: An experimental methodology using $20 \%$ carbon dioxide inhalation as an unconditioned stimulus. Behavior Therapy, 27(3). 391-415.

Westrup, D., Fremouw, W.J., Thompson, R.N., \& Lewis, S.F. (in press, 1998). The psychological impact of stalking on female undergraduates. Journal of Forensic Sciences.

Eifert, G.H., Thompson, R.N., Edwards, K., Frazer, N.L., Haddad, J.W., and Davig, J. (under review). The cardiac anxiety questionnaire: development and preliminary validity. Submission to Behaviour Research and Therapy (Behavioral Assessment Section).

\section{MANUSCRIPTS IN PROGRESS}

Thompson, R.N., Larkin, K., \& Beckner, D. Psychological responses to the implantable cardioverter defibrillator: a review and critique of the literature.

Eifert, G.H., Schermelleh-Engel, K., Thompson, R.N., \& Suchday, S. The pain regulation questionnaire: reliability and validity of a measure of pain competence, experience, and behavior.

Eifert, G., Edwards, K., Thompson, R.N., Haddad, W., Frazer, N. \& Davig, J. Panic symptoms in cardiac and non-cardiac chest pain patient samples.

\section{RESEARCH COMPLETED \DATA COLLECTED}

Westrup, D., Fremouw, W., \& Thompson, R.N. Attachment styles among acquaintance-stalking victims and age-matched controls in non-stalking relationships.

Thompson, R.N., Larkin, K.T., Beckner, D., \& Schmidt, S. Medical and psychological predictors of PTSD symptoms following myocardial infarction.

Thompson, R.N., Beckner, D., Palmer, D., Larkin, K.T., \& Schmidt, S. Prospective analysis of anxiety and depression in recipients of the implantable cardioverter defibrillator.

\section{RESEARCH IN PROGRESS}

Normative profiles on the Cognitive Capacity Screening Examination for Rural Medical Center Populations.

Development of the Mississippi Brief Aphasia Screen.

Correlates of the stages of consciousness: Assessment using behavioral and electrophysiolgic correlates.

\section{CONFERENCE PRESENTATIONS}

Eifert, G.H., Thompson, R.N., Sorrell, J.T. (1998, November). Validation of the cardiac anxiety questionnaire: preliminary data from cardiology patients. Paper presented at the annual meeting of the Association of the Advancement of Behavior Therapy, Washington, D.C.

Thompson, R.N. (1998, October). Psychological responses to the implantable cardioverter defibrillator: A review. Paper presented at the annual meeting of the Mississippi Psychological Association in Biloxi, MS.

Westrup. D., Thompson, R.N., \& Fremouw, W.H. (1997, November). Incidence and Impact of Stalking Among Female College Students. Paper presented at the annual meeting of the Association of the Advancement of Behavior Therapy, Miami, FL. 
Westrup, D., Thompson, R.N., \& Fremouw, W.H. (1997, November). Attachment Style and Stalking Behavior of Former Intimates: A predictor? Paper presented at the annual meeting of the Association for the Advancement of Behavior Therapy, Miami, FL.

Thompson, R.N., Beckner, D.H., Palmer, D., Larkin, K., Schmidt, S., \& Lobban, J. (1996, November). Anxiety and depression in recipients of the implantable cardioverter defibrillator. Poster presented at the Association for the Advancement of Behavior Therapy, New York, NY.

Thompson, R.N., Eifert, G.H., Weaver, K., Haddad, W., Frazer, N., \& Davig, J.P. (1996, November). Development and validation of a measure of heart-focused anxiety. Poster presented at the Association for the Advancement of Behavior Therapy, New York, NY.

Eifert, G.H., Thompson, R.N., Schermelleh-Engel, K., \& Suchday, S. (1996, March). The pain regulation questionnaire: reliability and validity of a measure of pain competence, experience, and behavior. Poster presented at International Society of Behavioral Medicine.

Forsyth, J.P., Eifert, G.H. \& Thompson, R.N. (1995, November). An experimental methodology for studying systemic alarms in fear conditioning using $20 \% \mathrm{CO}_{2}$ Inhalation. Poster presented at Association for the Advancement of Behavior Therapy, Washington, D.C.

Thompson, R.N., Forsyth, J.P., Davig, J.P., \& Eifert, G.H. (1995, April). Correlates of cardiophobic fears in college students. Paper presented at the annual meeting of the Anxiety Disorder's Association of America, Pittsburgh, PA.

Thompson, R.N., Davig, J.P., Forsyth, J.P. \& Eifert, G.H. (1994, November). Prevalence and significance of cardiophobic and generalized illness fears as a function of parental medical history. Paper presented at the annual meeting of the Association of the Advancement of Behavior Therapy, San Diego, CA.

\section{GRAND ROUNDS PRESENTATIONS}

Thompson, R.N. (1997). Assessment of the Stages of Consciousness. Grand Round presentation to Department of Psychiatry \& Human Behavior, University of Mississippi Medical Center, Jackson, MS.

Thompson, R.N. (1992). Depression. Grand Round presented to panel of supervising psychologists, Psychology Service, Veteran's Affairs Medical Center, Biloxi, MS.

\section{AD HOC REVIEWER FOR:}

Clinical Psychology and Psychotherapy

Journal of Cognitive Psychotherapy

Psychology of Addictive Behaviors

Diabetes Care 


\section{REFERENCES}

Mark Sherer, Ph.D., ABPP

Department of Neuropsychology

Mississippi Methodist Rehabilitation Center

1350 East Woodrow Wilson

Jackson, MS 39216

(601)364-3490

Email: marks@mmrcrehab.org

Thomas J. Payne, Ph.D.

Sonny Montgomery Jackson VAMC, Psychology Service 116B

1500 E. Woodrow Wilson Drive

Jackson, MS 39216

(601) 364-1259

E-mail: paynetj@fiona.umsmed.edu

Kevin Larkin, Ph.D.

Department of Psychology

West Virginia University

Box 6040, Oglebay Hall

Morgantown, WV 26506

(304) 293-2001,668

E-mail: klarkin@wvnvm.wvnet.edu

Phillip R. Godding, Ph.D.

Assistant Professor \&

Director of Behavioral Consultation \& Education Service

Sonny Montgomery Jackson VAMC, Psychology Service 116B

1500 E. Woodrow Wilson Drive

Jackson, MS 39216

(601) 364-1259

E-mail: godding@netdoor.com

William Fremouw, Ph.D.

Professor of Psychology

Department of Psychology

West Virginia University
Box 6040, Oglebay hall

Morgantown, WV 26506

(304)293-2001, 662

E-mail: fremouwwm@aol.com

Barry Edelstein, Ph.D.

Professor of Psychology

Department of Psychology

West Virginia University

Box 6040, Oglebay Hall

Morgantown, WV 26506

(304) 293-2001, 661

E-mail: U21b4@wvnvm.wvnet.edu 